\title{
La cerámica a mano de Nakūr (ss. IX-X) producción beréber medieval
}

\author{
Manuel Acién Almansa * \\ Patrice Cressier *** \\ Larbi Erbati **** \\ Maurice Picon $* * * * *$
}

Los resultados aquí expuestos han sido obtenidos en el marco de un proyecto de cooperación arqueológica franco-marroquí, Casa de Velázquez-INSAP I, titulado Génesis de la ciudad islámica en Marruecos (Nakūr, Agmāt, Tāmdült), cuyo objetivo es aportar precisiones sobre el proceso de desarrollo urbano que conoce el Magreb occidental en los ss. VIII-IX (con algunas prolongaciones hasta el s. X). La aproximación a este fenómeno se hace a través de tres asentamientos medievales, mencionados tempranamente como ciudades (madina-s) por las fuentes escritas y significativos de tres ámbitos geográficos muy distintos del actual Marruecos: el Rif, montaña mediterránea abierta a alAndalus (Nakūr); el dir del Alto Atlas, zona de intercambio llanura-montaña (Agmāt) y la franja pre-sahariana, mirando hacia África (Tāmdūlt). Estas tres ciudades nacieron por voluntad propia de los grupos concernidos - con o sin intervención de un agente exterior-, integradas en un tejido tribal beréber -por otra parte apenas o para nada romanizado-, obediencia cultural beréber todavía muy marcada hoy día, en particular por el idioma.

Desde el punto de vista práctico se trata, gracias al análisis de foto-interpretación, a prospecciones temáticas y a sondeos localizados, de precisar los grandes rasgos urbanísticos de estas ciudades (organización del espacio, características constructivas), de reunir datos sobre su cultura material (siendo una de las prioridades la elaboración de una crono-tipología de la cerámica) y de evaluar el papel de la explotación de los recursos naturales (agricultura de regadío, minería, etc.) en aquel proceso de urbanización del que quedaría por confirmar además -o no- el paralelismo con los de arabización e islamización.

De las tres ciudades objeto de esta investigación, Nakūr es la que resulta más interesante para los estudiosos de al-Andalus, para la que mayor información se puede obtener de una aproximación comparatista: no sólo por la simple proximidad geográfica, sino también por las evoluciones históricas complementarias sufridas por los dos Estados (sin olvidarse por supuesto del fuerte desequilibrio existente entre uno y otro).

\section{El emirato de Nakūr y su capital}

Ya al-Ya'qūbī nos relata que, en su camino de Oriente a Córdoba 'Abd-al-Raḥmān pasó por Nakūr y que fue su emir el que le permitió cruzar el Mediterráneo ${ }^{2}$. El reino había sido fundado a principios del siglo VIII por șāliḥ ibn Manșūr de supuesto origen himyañ (yemení) y al

\footnotetext{
* Universidad de Málaga. ***asa de Velázquez/UMR 5648-CNRS. ****INSAP, Rabat. *****aboratoire de Céramologie-CNRS, Lyon. I 1995-1999; co-dirección P. Cressier y L. Erbati. En su financiación intervienen también el Ministerio de Asuntos Exteriores francés y el equipo UMR 5648 del CNRS.

2 Dado el limitado espacio disponible aquí, no intentaremos una reconstrucción exhaustiva de la historia de Nakūr. Aunque ésta queda por hacer, se puede remitir en un primer tiempo a CAGIGAS (195I), GOZALBES BUSTO (I989) y, más recientemente, SIRAJ (1995).
} 
que, según Ibn Jaldūn el califa omeya de Damasco había dado este territorio en iqtāi', en 709. șālih ibn Manșūr residió y murió en la tribu de Timsaman y, después de que su hijo, Idrīs ibn șâlih hubiese fijado un zoco intertribal de Banū Waryagal y Timsaman en la orilla del río Nakūr, fue su nieto Saīd ibn Idrīs quien en este mismo sitio fundó la ciudad de Nakūr, en una fecha nunca precisada por las fuentes escritas pero que podemos fijar a finales de la primera mitad del $\mathrm{s}$. IX. Durante el siglo $X$ el reino de Nakūr es un Estado tapón entre los dos grandes califatos de Occidente, el omeya de Córdoba y el fatimí de Ifrīqiya; aunque siempre de obediencia omeya, y a pesar de que un soberano cordobés, por lo menos, acuñase moneda en Nakūr (Hișām II), nunca llegó a ser anexionado como lo fueron en ciertas ocasiones Țanŷa, Sabta o Malīla y debió ser más bien una suerte de protectorado. Según los textos, fue arrasada la ciudad (¿total o parcialmente?) en tres ocasiones: por los Normandos hacia 858, por Mașāla general fatimí en 917 y por Abū l-'Āfiya en 936. La destrucción final se suele atribuir a Yūsuf ibn Tāșufin el almorávide, en el siglo Xl; pero algunos indicios, tales como la confusión frecuente de al-Mazimma, su puerto principal, y Nakūr o el hecho de que la dinastía saalihí desaparezca como tal antes, a principios del s. Xl, podrían dejar entender que el centro político ya se había desplazado de la orilla del río a la colina costera frente a "Haŷar Nakūr" el actual Peñón de Alhucemas.

La mejor descripción de la ciudad nos la ofrece al-Bakrī. Según este autor, estaba rodeada por una muralla de tierra (libn) con cuatro puertas (de Sulaymān al sur, de al-Mușallà al oeste, de los Judíos al norte y de los Banū Waryagal entre el sureste y el norte); disponía de baños y zocos y su mezquita "construida a semejanza de la de Alejandría" contaba con columnas de madera de tuya. Existía un arrabal de los Eslavones (qaryat al-Saqāliba); estaba Nakūr rodeada de huertos y molinos.

\section{El yacimiento}

El yacimiento arqueológico de Nakūr se encuentra a unos $17 \mathrm{~km}$ del mar en la orilla izquierda de un meandro del río Nakūr; ocupa dos colinas separadas por la carretera nacional de Taza a Al-Hoceima, en el punto en el que el valle se ensancha para dejar sitio a la llanura costera. Una presa monumental edificada en 1980 se ancla en la colina principal hoy ocupada por las casetas de los peones que la construyeron.

Fotointerpretación y prospecciones de superficie han mostrado que la ciudad contaba con dos recintos elípticos concéntricos con posible reducto central; su eje mayor medía unos $900 \mathrm{~m}$. En la orilla derecha del río un barrio abierto estaba dedicado a la transformación del mineral de hierro tal como lo demuestran las abundantes escorias en superficie mezcladas con cerámica medieval.

Tres sondeos han sido realizados en 1996: el primero en la zona de contacto entre el supuesto "alcázar" y el interior del primer recinto ha sido casi totalmente improductivo; el tercero, en la zona más alta de este reducto central, ha mostrado la existencia de un edificio hipóstilo con columnas de madera, recubierto de tejas (iel palacio, la mezquita?), sin ningún fragmento de cerámica; el segundo, implantado sobre la muralla interior, es el que ha dado el abundante material estudiado aquí, en un contexto que parece ser el de vertedero (presencia del cuerpo entero de una vaca, restos de huesos quemados, fragmentos de vidrio y de metal).

Tal como veremos más adelante la cerámica hallada se puede dividir en tres conjuntos: la cerámica vidriada cuyo repertorio de formas y de decoración se enmarca perfectamente en lo que se conoce de las producciones mediterráneas del momento, la cerámica común a torno y la cerámica común sin tornear objeto del presente estudio.

Antes de entrar de lleno en el tema, conviene preguntarse sobre lo que hoy día se sabe de esta cerámica a mano medieval de Marruecos.

\section{La cerámica medieval a mano de Marrue- cos: una producción casi desconocida}

Durante numerosos años - de hecho durante toda la época colonial-, la aproximación a la cerámica a mano marroquí ha sido exclusiva- 
mente etnográfica, sin que los arqueólogos hubiesen mostrado jamás el mínimo interés hacia ella ${ }^{3}$. Esta falta de interés se debió ante todo a dos errores de percepción -por otra parte muy comprensibles en el contexto cientííco de la época-: el primero era el aproximarse a la cerámica en general más como un indicio cronológico que como el indicio cultural y social que es también y ante todo; el segundo era el considerar que la cerámica a mano era una producción sin casi evolución tipológica y formal desde tiempos prehistóricos, con las consecuencias que ello suponía respecto al primer punto. A esta percepción errónea se le venía añadiendo otra equivocación, debida esta vez a los límites de la información etnográfica, y que hacía de la cerámica pintada la cerámica beréber por excelencia.

Con todo, el balance, cincuenta años después, no es totalmente negativo; aquí están los trabajos de A. Delpy y J. Herber u otros, trabajos valiosos aunque -por las razones ya evocadas- no siempre aprovechables desde la perspectiva arqueológica. Sus mayores logros residen en presentar series morfológicas cuyas funciones están claramente identificadas, testimonios sobre las condiciones materiales de fabricación, así como glosarios específicos más o menos detallados ${ }^{4}$.

Exceptuando de la investigación pionera, de cierta forma prematura, llevada a cabo sobre los despoblados de la zona de Oujda por J. Marion (MARION, 1957: f. 8 y p. 163) ${ }^{5}$, los primeros trabajos arqueológicos que toman en cuenta explícitamente la cerámica a mano marroquí no se publican hasta mediados de los años ochenta. Aunque el espacio reservado a aquéIla con respecto a la cerámica a torno es todavía casi testimonial, no dejan de ofrecer los úni- cos datos comparativos aprovechables, tal y como veremos más adelante: al-Bașra (REDMAN, 1983-84: f. 20 y p. 332, y BENCO, 1987: pp. 63-66 y f. 5.I), Tigisas (BAZZANA et al., 1983-84: f. 17- 18 y 44 I-447), el mismo Tigisas, Tarța, Targa y Ŷabha (BAZZANA, MONTMESSIN, 1995: f. 4), Badīs (REDMAN, $1983-$ 1984: f. 26 y p. 337) o el propio Nakūr (Id.: f. 19 y p. 34I). Mención aparte merecen las producciones a mano de Ceuta, ciudad que muy pronto constituyó un eslabón entre al-Andalus y el Magreb occidental, estudiadas en el marco de una aproximación global a su cerámica medieval (FERNÁNDEZ SOTELO, 1988: III, pp. 3-7).

Recientemente tres investigaciones -por otra parte de muy distinta índole - han permitido progresar en el conocimiento de la cerámica a mano, incluida la medieval, del norte de Marruecos. A partir de un ejemplo concreto, el de unos fragmentos hallados en una cueva del Monte Musa, al sur de Ceuta, y atribuidas a época protohistórica, J. Onrubia ha mostrado lo peligroso que sería asegurar una continuidad de la cerámica pintada "beréber" a lo largo de un periodo tan largo, así como el carácter excepcional de este tipo de producción en aquellas épocas remotas (ONRUBIA, 1995). M. Picon, por su parte, retomando y homogeneizando una serie de datos etnoarqueológicos recogidos en todo Marruecos, propone nuevas lecturas de la coexistencia de cerámica a mano y de cerámica torneada y confirma que, lejos de ser un rasgo de arcaísmo, el adoptar la primera constituye una verdadera y racional elección tecnológica (PICON, 1995). Por último, en un trabajo todavía inédito, R. Elhraiki e Y. Montmessin han intentado establecer la naturaleza de los lazos entre cerámicas medievales a mano de la zona costera de Targa-Tigisas y las producciones tradicionales actuales y sub-actuales de Faran Alī (a unos kilómetros al sur de Oued Laou) ${ }^{6}$.

3 Varios testimonios coinciden en que la norma de las excavaciones realizadas durante aquellos años era el deshacerse de este material sin, ni siquiera, describirlo.

4 Un trabajo de investigación de primera mano realizado por A. Ricard de 1931 a 1934 sobre la cerámica común marroquí quedó inédito. Se conserva un manuscrito (Contribution à l'étude des poteries communes du Maroc. lère Partie : les poteries féminines) en el "Département d'Afrique blanche et du Proche-Orient" del Musée de l'Homme de París: ONRUBIA, 1995 : p. I35, nota 17.

5 Prematura porque, en aquel momento, ni siquiera para la cerámica a torno se tenían puntos de referencia válidos, lo que excluía toda veleidad de datación.

6 Investigación realizada en el marco del proyecto Casa de Velázquez/INSAP, Prospection archéologique dans les Jbala-Ghomara co-dirigido por A. Touri, A. Bazzana y P. Cressier. 
En todo caso, la cerámica de Nakūr, aquí presentada, será la primera serie de cerámica a mano medieval producida por un grupo tribal beréber en haberse beneficiado de un estudio sistemático -aunque todavía no exhaustivo-. Sin ánimo de hacer creer que es representativa del conjunto de las producciones beréberes magrebíes de la Alta Edad Media, no cabe duda que, dadas las características del reino de Nakūr tal como las describimos más arriba, está llamada a constituir un punto de referencia importante tanto para futuras investigaciones en Marruecos como para cualquier intento de debatir la atribución cultural de las producciones cerámicas de alta época en al-Andalus.

\section{La cerámica medieval a mano de Nakūr}

Por lo que respecta a la cerámica modelada a mano de la excavación de Nakūr y lo que ésta puede aportar al conocimiento de la cerámica beréber en general, lo primero que se ha de aclarar es que el planteamiento de si existe una identidad en la cerámica beréber a través de los siglos sería, en principio, una cuestión tan absurda como intentar establecer una identidad de la cerámica hispánica o, con un ejemplo más apropiado, tratar de definir la identidad o los rasgos comunes y propios de la cerámica latina. Sin embargo, el problema adquiere otra dimensión si lo que entendemos por "beréber" son las distintas sociedades tribales beréberes que, de acuerdo con lo expuesto por A. Laroui para la historia del Magreb (LAROUI, 1975), han existido siempre como tales sociedades tribales, si bien con notables diferencias en cuanto a su implantación geográfica en las distintas etapas históricas.

Parece ser que es esta segunda formulación del problema la que subyace en la mayoría de los autores que se han acercado al tema, pues, por ejemplo, nunca se identifican como cerámica beréber las producciones de época almohade halladas en el Magreb, pese a que el origen beréber de los Almohades es algo incuestionable. Pero aun si nos limitamos a esa caracterización de grupos tribales beréberes en el Magreb, resulta cuestionable la existencia de una identidad, o continuidad, si tenemos en cuenta los distintos componentes del material cerámico, como técnica empleada, tratamiento de las superficies, tipología, función y decoración. Pues lo que los investigadores denominan como cerámica "tradicional", "popular", "grosera", etc., y que, de acuerdo con estos autores, se dan tanto en los niveles históricos como en la actualidad, en realidad lo que identifican bajo tales denominaciones se refiere tan sólo al hecho de estar elaboradas a mano y a la ausencia de vidriado, mientras que no se suele aludir al tratamiento de la superficie ni a la decoración, los perfiles dibujados son escasísimos, y en cuanto a la función, los autores observan la limitación de la cerámica histórica a las formas de cocina, o cocina y almacenamiento en el caso de Siŷilmāsa (BAZZANA et al., 1983-84; REDMAN, 1983-84; BENCO, 1987; BAZZANA, MONTMESSIN, 1995; TAOUCHIKHT, 1995).

Sobre este último aspecto, el de la función, los estudios etno-arqueológicos proporcionan una constatación importante, pues como se verá más adelante, en los casos analizados, la totalidad de la vajilla está elaborada a mano, a diferencia de la procedente de los yacimientos, en los que ésta representa tan sólo un porcentaje limitado y se concreta en una porción de los útiles de cocina.

Es lo que se deduce de los casos mejor estudiados, como en al-Bașra, donde las proporciones son un $5,4 \%$ de cerámica a mano, un $2 \%$ de vidriada, y por tanto, un $92,6 \%$ de cerámica común torneada (BENCO, 1987); un porcentaje similar de vajilla a mano se encuentra en Qșar al-Sagiri, si bien aquí con una cronología más tardía, mientras que en los yacimientos de Nakūr y Badis la proporción de cerámica modelada sería mayor (REDMAN, 1983-84). Estas diferencias las entiende Ch. Redman, con independencia de las diferentes cronologías, como el resultado de una mayor presencia de los rasgos urbanos en los dos primeros yacimientos, frente a los casos de Nakūr y Badīs que estarían más imbricados en el mundo rural (REDMAN, 1983) mientras que por su parte, $\mathrm{N}$. Benco piensa en una transformación del gusto en los dos primeros lugares, que llevaría a sus habitantes a una preferencia por la cerámica torneada (BENCO, 1987). También es reducida la presencia de cerámica a mano en el yacimiento de Tigisas, con una cronología de los ss. XIII-XIV, pues en el 
inventario publicado tan sólo se cuentan de seis a ocho piezas con tal técnica de un total de cincuenta y una (BAZZANA et al., 1983-84) 7 .

Si nos centramos en el caso de Nakūr, el estudio más detallado de su cerámica es el de $\mathrm{N}$. Benco (BENCO, 1987: p. 137), donde se hace una comparación con el material de al-Bașra y se extraen las siguientes conclusiones: en primer lugar, una mayor homogeneidad en el conjunto de la cerámica de Nakūr, frente a los importantes cambios que observa en las tres fases que define para el material de al-Bașra; en segundo lugar, como ya se ha indicado, una mayor presencia de la cerámica a mano en el primer yacimiento, que evalúa en un $30 \%$; como tercer punto, la existencia de unas ciertas similitudes formales, que consisten fundamentalmente en la preponderancia de las basas planas o ligeramente convexas, como rasgo atribuible a toda la producción; y en cuanto a las diferencias tipológicas enumera tres tipos desconocidos en alBașra, el trípode con doble carena de forma cerrada, la jarrita con filtro y el candil de pie alto ("pedestaled lamp"), provenientes todos ellos de los niveles inferiores de la excavación; y en cuarto lugar, como consecuencia de lo anterior, una datación de los ss. XI -XII para el yacimiento de Nakūr.

La cronología propuesta es algo que no podemos compartir, debido a la tipología general y a los paralelismos más fiables que se pueden establecer, pero antes se ha de observar que la alusión al candil de pie alto tan sólo aparece en esta obra de N. Benco, no está descrito ni dibujado ni en éste ni en ningún otro trabajo de la autora, al igual que tampoco se alude a él en las diversas publicaciones de Ch. Redman sobre el tema ${ }^{8}$. Por nuestra parte, compartimos con la arqueóloga norteamericana la observación de homogeneidad, en el sentido de que no se advierten diferencias notables ni ninguna solución de continuidad en la presencia de tipos y técnicas a lo largo de toda la secuencia estratigráfica, por lo que la caracterización cronológica se ha de establecer de forma global.
Entre los elementos cronológicos derivados de la tipología general, contamos con los grandes contenedores tipo dolium (lám II, f. I-3), así como con la presencia exclusiva del candil de piquera (lám I, f. 6-8), mientras que los paralelismos -o más bien productos de importaciónse refieren a la vajilla de verde y manganeso: dos redomas, una jofaina y un ataifor (lám I, f. I-4), el jarrito tipo Pechina (lám I, f. I2), y el ataifor vidriado en amarillo con motivo epigráfico almulk, semejante a las producciones aglabíes y fatimíes de Ifrīqiya (lám I, f. I3). Con una precisión cronológica menor, se pueden destacar una jarrita de cuerda seca parcial (lám I, f. 5), los jarros bizcochados con decoración en relieve (lám I, f. 9-1 I ), y dos trípodes con forma cerrada (lám II, f. 5-6), semejantes al ya citado de Benco y con cierto paralelismo con el hallado en Tegdaoust que se data en 953-973 (DEVISSE, PICON, 1995: f. 6). Finalmente, incluimos entre estas piezas de referencia, el único fragmento de cerámica pintada hallado en la excavación, un borde de marmita o gran jarra (lám II, f. 4), así como una basa bizcochada en foma de umbo (lám I, f. I4), por la posibilidad de que una pieza semejante a ésta sea la identificada por N. Benco como candil de pie alto.

En consecuencia, creemos que es más correcta una datación de los ss. IX-X para el conjunto de las producciones del yacimiento, aunque se puede aceptar también una tímida presencia del s. Xl, debido a la pervivencia del verde y manganeso y la aparición de la jarrita con cuerda seca parcial, y asimismo los jarros con decoración en relieve se pueden considerar como un precedente de los estampillados, pero resulta claro que los datos más evidentes apuntan a la primera cronología propuesta.

Por lo que respecta a la cerámica modelada a mano, nuestro porcentaje viene a coincidir con el indicado por Ch. Redman y N. Benco para el yacimiento, por lo que la mayor parte de la producción la constituye la cerámica común a torno, pues la vidriada se limita tan sólo a unos veinte fragmentos, mientras que, como se ha

7 Resultan dudosas a partir de la descripción las piezas n $\mid$ I y 37 del inventario.

8 Nosotros no pudimos encontrarlo al reexaminar la cerámica de dicha excavación, depositada en la Delegación del Ministerio de Asuntos Culturales de Tánger. 
podido ver, la cerámica pintada es prácticamente inexistente. Con dicha técnica se elaboran tan sólo tres tipos, a saber, las grandes tapaderas discoidales, cazuelas y marmitas, con una presencia mucho más abundante de estos dos últimos tipos, mientras que el primero tiene una significación bastante menor. De éstas, las tapaderas, se encuentran fragmentos con claros signos de exposición al fuego, lo que demuestra su carácter polifuncional, a pesar de la denominación que se le viene dando, y al mismo tiempo nos delimita la función de la serie como vajilla de cocina casi en exclusividad, superando ampliamente en el yacimiento a la fabricada a torno con la misma funcionalidad.

Las tapaderas representadas (lám III, f. I-3) proceden del sondeo 2, nivel I, su diámetro oscila entre 26 y $24 \mathrm{~cm}$, el aspecto de las pastas es rojizo-grisáceo (lám III, f. I y 2) o marrón (lám III, f. 3), y también difieren en los desengrasantes, de gran tamaño (lám III, f. 2) o pequeño y color claro (lám III, f. 3); los rebordes verticales pueden ser: fino de sección semicircular (lám III, f. I), o más ancho con digitaciones (lám III, f. 2 y 3); los fragmentos identificados se limitan a la parte del borde, por lo que desconocemos si existió algún elemento prensil en el centro o, por el contrario, si serían simples superficies lisas.

El sondeo I proporcionó bastante menos cerámica, como ha quedado dicho, pero entre las piezas recuperadas también se encuentran las fabricadas a mano, que se representan en la lámina III, marmitas (lám III, f. 4-7) y cazuelas (lám III, f. 8- I0) Todas las marmitas presentan pastas rojizas y desengrasante abundante, y se da una diversidad de diámetros desde los $14 \mathrm{~cm}$ (lám f. III, 4) a 24 cm (lám III, f. 7); las paredes suelen ser rectas, convergentes hacia el borde, y éste se consigue con un simple adelgazamiento de la pasta y seccion semicircular, apareciendo en algún caso una ligera tendencia hacia el borde exvasado (lám III, f. 4); los elementos de aprehensión conservados se limitan a un pequeño mamelón casi cónico (lám III, f. 4) y bandas excisas con digitaciones (lám III, f. 5 y 7).
Las cazuelas ofrecen una mayor diversidad en el color de las pastas, marrón (lám III, f. 8), grisácea (lám III, f. 9) y rojiza-marrón (lám III, f. I0), todas ellas con abundante desengrasante, en ocasiones de gran tamaño (lám III, f. 8 y I0). Las paredes son gruesas, rectas y divergentes hacia el borde (lám III, f. 8) o bien curvas (lám III, f. 9 y 10), y los diámetros que resultan son notables: 26 cm (lám III, f. 8 y 9), o realmente grande, 36 cm (lám III, f. I0); como elementos de aprehensión se repiten las bandas excisas, con digitaciones (lám III, f. 9) o impresiones en forma de ángulo (lám III, f. 8).

Como se ha venido repitiendo, la mayor parte del material procede del sondeo $2 y$, de acuerdo con la homogeneidad también comentada, en éste se recuperó asimismo casi la totalidad de la cerámica modelada a mano en la que, además de las tapaderas discoidales ya vistas, la tipología se reduce a cazuelas y marmitas; éstas las presentamos según la secuencia estratigráfica, a partir de los niveles superiores, en las láminas IV y V, cazuelas, y VI y VII, marmitas. En cuanto a las primeras, se elaboran con una diversidad de pastas de las que resultan tonos rojizos (lám IV, f. I; lám V, f. 4 y 7), marrón claro (lám IV, f. 3 y 5), o más comúnmente marrón-grisáceo, a veces con notable contraste entre el interior de la pasta, gris (lám IV, f. 3), y las superficies, debido al grosor de las paredes, y con diferencias más atenuadas entre la superficie interior y la exterior, ésta con una tendencia hacia tonos más grisáceos o negruzcos que los que aparecen en el interior de las piezas; el desengrasante se aprecia de manera abundante en la mayoría de las cazuelas, con la excepción de la lámina $\vee$, f. 7 en que es escaso, y en ocasiones de gran tamaño (lám IV, f. 3 y 6; lám V, f. 6). También difieren entre sí en las dimensiones, con diámetros en el borde desde $34 \mathrm{~cm}$. (lám V, f. 4) a $20 \mathrm{~cm}$. (lám $V, f .7$ ), si bien con una media en torno a los $26 \mathrm{~cm}$., mientras que la diversidad formal es menos acusada, con paredes rectas y divergentes por lo general 9 , pero con cierta curvatura en un caso (lám IV, f. I), curvatura que comparten en la unión entre

\footnotetext{
9 En el caso de la pieza lám. IV, f. 5, con paredes bastante verticales, cabe la posibilidad de que se trate de una marmita de gran tamaño.
} 
paredes y basa, salvo en la lámina IV, f. 4 con acusada carena; los bordes suelen ser rectos con sección redondeada, si bien en algunos casos se aprecian bordes ligeramente exvasados con sección biselada en el interior (lám IV, f. 3; lám V, f. I y 3); y donde la uniformidad resulta mayor es en el sistema de aprehensión, mediante mamelones, en un caso de gran tamaño (lám V, f. 5), puesto que de la cinta corrida con digitaciones tan sólo se cuenta un ejemplar (lám V, f. 3), mientras que los elementos decorativos son inexistentes, con una única salvedad, la pequeña cazuela de la lámina $\vee, f .7$, que porta tres líneas de impresiones en forma de hojitas.

Los resultados de la cocción de las marmitas son pastas generalmente con tonalidades marrón-grisáceas, en algunos casos con un marrón claro (lám VI, f. I y 4), en menor medida rojizas (lám VII, f. 3) o grises (lám VII, f. 2), y las diferencias entre las superficies interior $y$ exterior resultan menos acusadas que en las cazuelas, si bien contamos con un caso de notable contraste, grisácea en el interior y con el exterior pajizo (lám VII, f. 5), y asimismo son frecuentes los restos de exposición al fuego en las superficies exteriores, pero también en el interior (lám VI, f. 9); también a semejanza con las cazuelas, los desengrasantes aparecen en cantidades notables, con la excepción de la pequeña marmita de la lámina VII, f. I en que es escaso, y curiosamente los de mayor tamaño se dan en marmitas también pequeñas (lám VII, f. 2 y 4); la diversidad de tamaños es más acusada aún en esta serie que en las cazuelas, con diámetros en los bordes que oscilan entre los 23 cm. (lám VI, f. 7) y los $9 \mathrm{~cm}$. (lám VII, f. 4), siendo de destacar la relativa abundancia de marmitas con muy escasa capacidad (lám VII, f. I, 2 y 4). En las formas predomina la tendencia a la globular con la basa plana cuando se ha podido determinar (lám VII, f. 4), y los bordes escasamente destacados (lám VI, f. 4) pero con frecuencia adelgazados y biselados en el interior; entre los elementos de sujeción se da también el mamelón (lám Vl, f. 7), pero abundan más que en las cazuelas las bandas excisas, las cuales se presentan con un amplio repertorio de digitaciones de diverso tamaño (lám VI, f. I; lám VII, f. 6) o combinaciones de éstas y mamelón (lám $\mathrm{VI}, \mathrm{f}$. 2), banda con incisiones y lengüeta (lám VI, f. 8) y banda con impresiones en forma de hojita (lám VI, f. 9). Este último ejemplo nos introduce en el tema de la decoración, en el que se puede observar la diferencia más neta con respecto a las cazuelas, pues en las marmitas además de abundantes son bastante variados, con simples incisiones o impresiones en sentido diagonal (lám VI, f. 4, 5; lám VII, f. 3), líneas quebradas incisas (lám VII, f. 4, 7, 8), incisas onduladas combinadas con línea horizontal y pequeñas incisiones (lám VII, f. 5), o bien con impresiones en forma de pequeñas hojas (lám VII, f. 2), así como agrupaciones de este último motivo (lám VII, f. I).

De las descripciones anteriores se puede inferir una cierta homogeneidad formal para los tres tipos representados, cuyas características generales serían las paredes rectas y divergentes para las cazuelas y la tendencia hacia la forma globular en las marmitas, unas y otras con basas planas o ligeramente convexas y con elementos de aprehensión a base de mamelones y bandas excisas; es de destacar, por lo que respecta a la tipología general, la ausencia de asas de puente, que sí se da en la coetánea vajllla de cocina a torno, así como la decoración a base de peines o tratamientos de superficies mediante alisado, espatulado, etc. Pero junto con dicha semejanza formal se aprecian notables diferencias en las pastas utilizadas así como en los resultados de la cocción, diferencias que se hacen mayores en cuanto a las dimensiones y capacidades, tanto en cazuelas como en marmitas, y asimismo los motivos decorativos en las marmitas, cuando aparecen, se cuentan tantos como ejemplares, si bien con un repertorio limitado a incisiones y pequeñas impresiones. En consecuencia, se ha de pensar en un alto número de productores para esta vajilla, los cuales se limitan a elaborar unos escasísimos tipos de recipientes para cocinar, que responden a una cierta homogeneidad formal, todo lo cual obedece quizás a una distribución de tipo familiar.

Como ya se ha explicado, de los posibles paralelos magrebíes son muy escasos los representados, y éstos responden a cronologías muy variadas, por lo que no es de extrañar que las semejanzas sean bastante reducidas $y$, por el contrario, predominen las diferencias en cuanto 
a la tipología se refiere, pues como ya ha quedado dicho, las similitudes que se defienden en la bibliografía se limitan a la técnica de elaboración a mano. Así, de Aïn Taïret, donde no se dan fechas, se nos dice que la gran masa de cerámica está fabricada sin torno, y de ésta la mayoría corresponde a "marmitas groseras", entre las cuales se puede encontrar la de cuerpo globular y banda excisa con digitaciones, pero con la variante tipológica de cuello claramente marcado y borde ligeramente exvasado (MARION, 1957: f. 8, 4). En Tigisas, con una cronología centrada en los ss. XIII-XIV, aparece la cazuela con asa de mamelón y paredes muy curvas (BAZZANA et al.: f. 16, 22), pero a diferencia de nuestro yacimiento las marmitas llevan asas de sección triangular perforadas, del tipo "de orejas" (id.: f. 17, 4), o bien de puente (BAZZANA, MONTMESSIN, 1995: f. 4, 6 y 8); y algo semejante sucede en el resto de yacimientos presentados por estos autores, puesto que de Tarǵa se publica una pequeña marmita de forma globular, pero con el borde claramente exvasado y sin ningún tipo de decoración, aparecida junto con material de tipo nazarí (BAZZANA, MONTMESSIN, 1995: f. 4, I), mientras que de $\hat{Y}$ abha se representa una marmita con mamelones y sin decorar, junto con otras de cuello claramente diferenciado, con borde recto y decoración de peine en la unión del cuello con el galbo, o cuello muy curvo y marcada incisión horizontal a la altura del hombro, con una cronología de los ss. XII-XIII (BAZZANA, MONTMESSIN, 1995: f. 4, 3-5). En Badīs, donde aparece una alta proporción de cerámica modelada a mano, un 46\%, la tipología es bastante más amplia, pues la forma más común es un ataifor bruñido -a veces pintado-, que alcanza el 49\% de la producción sin torno; se dan también los grandes jarros, e incluso el canjilón de noria, pero la marmita es bitroncocónica y con grandes asas de puente (REDMAN, 1983-84: f. 26, A), por lo que el único paralelo con Nakūr se encuentra en la tapadera discoidal (id.: f. 26, C). Lógicamente, debido a la cronología que comparten, los paralelos más firmes son los proporcionados por al-Bașra, con bandas aplicadas con digitaciones en cazuelas y marmitas, las primeras con paredes rectas y divergentes, y las segundas con forma globular (REDMAN, 1983-84: f. 20, T y V) a semejanza de las de Nakūr, pero aparece también un vaso con base plana y paredes totalmente verticales (id.: f. 20, U) sin pre- sencia en nuestro yacimiento, a lo que añade $\mathrm{N}$. Benco otra marmita globular con decoración incisa en zig-zag en el estrangulamiento del cuello y borde muy exvasado (BENCO, 1987: f. 5. I, a).

Finalmente, entre los posibles paralelos norteafricanos, tenemos el caso de la ciudad de Ceuta, donde se distinguen diversas series de cerámica a mano, con una cronología de los ss. X-XI (FERNÁNDEZ SOTELO, 1988: lám III, pp. 6-7). Dichas series comprenden tipologías bastante diferentes de las nuestras, como las marmitas muy grandes de cuerpo globular o piriforme generalmente con dos asas de puente (id.: f.l), marmitas de cuerpo bitroncocónico y grandes asas, semejantes a la de Badīs (id.: f. 4), la que el autor denomina como olla con pitorro (id.: f. 8 , a), o las de base plana y paredes verticales que se curvan para formar el borde, con pequeñas asas de puente y lengüetas, muy semejantes a las del sureste peninsular (id.: f. 45); pero también se dan formas más parecidas, como la marmita globular con banda excisa digitada y mamelón (id.: f. 2, 9), la cazuela de paredes divergentes con banda digitada (id.: fig 6, c), o las marmitas globulares de pequeño tamaño (id.: f. 6, a y b), y del mismo modo también son frecuentes los trazos incisos en sentido diagonal (id.: f. 2, c; f. 3, a y b), al igual que están presentes los pequeños mamelones casi cónicos, aunque en esta serie los más frecuentes son los de tipo lengüeta, rectas o curvas.

También se pueden apreciar relaciones de nuestro grupo con las cerámicas andalusíes contemporáneas, mejor estudiadas, en especial con el denominado grupo del sureste peninsular, pues ya se apuntó la gran similitud entre un tipo de marmita de al-Bașra (BENCO, 1987: lám 5, I, C) y otra procedente de Bezmiliana (ACIÉN, MARTíNEZ, 1989: f. I, 5), comparación que ahora se puede extender a Nakūr, puesto que se trata de la marmita globular con banda excisa digitada. Sin embargo, se ha de aclarar que la marmita de Bezmiliana con la que se establece esa estrecha semejanza apareció descontextualizada, y responde a un ejemplar único en el yacimiento, tanto por el tipo de pasta, de color marrón oscuro y bastante más gruesa que las restantes, como por el elemento prensil, pues lo usual es el pequeño mamelón en forma de lengüeta 
alternando con asas de puente. Por tanto, si hacemos caso omiso de este ejemplar único, la principal semejanza entre nuestra serie y la del grupo del sureste la encontramos en el aspecto funcional, o sea, en el uso primordial como vajilla de cocina; pues también se pueden apreciar diferencias tipológicas, al igual que encontrábamos en los yacimientos marroquíes.

En efecto, las variantes indicadas para la generalidad de Bezmiliana se repiten también en el caso de la ciudad de Málaga, aquí con una mayor verticalidad en las paredes de las marmitas (ACIÉN, MARTÍNEZ, 1989: f. 1, 6 y 10), verticalidad de paredes que asimismo se encuentra en el tipo de marmita predominante de entre las datadas en el s. IX para la zona de Tudmîr, donde también aparece la tapadera discoidal y la marmita de cuerpo globular pero con cuello desarrollado y borde exvasado (GUTIÉRREZ, 1993: f. 5); y ese mismo primer tipo de marmita es el que continúa en el s. $X$, si bien ahora con proliferación de decoraciones a base de peines (GUTIÉRREZ, 1993: f. 9). En el yacimiento de Pechina se encuentran asimismo los tres tipos de cerámica modelada: las tapaderas discoidales, en bastantes ocasiones con asa de puente (CASTILLO, MARTíNEZ, 1993: lám XIII, f. 8- I2); las cazuelas y las marmitas, con asidero casi exclusivamente de mamelones en forma de lengüeta, y estas últimas, las marmitas, de un tipo muy semejante al señalado para la zona malagueña y murciana, con la novedad aquí del vidriado interior y los trazos de pintura en el exterior, pero sin ningún tipo de decoración incisa ni bandas excisas digitadas (CASTILLO, MARTíNEZ, I993: lám XIV, f. I-4; lám XIII, f. 14). Sí conviene destacar entre las marmitas de Pechina la presencia de la de muy pequeño tamaño y forma globular, a semejanza de las de Nakūr, pero con pequeños mamelones y sin ningún tipo de decoración (CASTILLO, MARTíNEZ, 1993: lám XIII, 7); se trata de un elemento culinario que debió tener cierta frecuencia en la época, pues también aparece entre los materlales emirales de Cercadillla (Córdoba), aunque en este caso, al igual que toda la producción del yacimiento, fabricado con torno alto (FUERTES, GONZÁLEZ, 1994: f. 8, I y 3).

Las mismas variantes tipológicas y similitudes funcionales y técnicas se pueden encontrar en otros yacimientos contemporáneos, como el granadino de El Maraute, donde un ejemplar de marmita presenta la banda aplicada con digitaciones y mamelones en sentido radial (GÓMEZ BECERRA, 1993: f. 1 y 2), pero resulta más inesperado las semejanzas que se pueden constatar con recientes hallazgos de cronologías bastante más antiguas, como las datadas del s. VI en la ciudad de Málaga, donde se dan las cazuelas de paredes curvas con bandas de digitaciones (NAVARRO LUENGO et al., 1997: p. 92), O las también marmitas y cazuelas de paredes curvas y mamelones como elemento de aprensión aparecidas en El Puerto de Santa María, a las que se les otorga una cronología asimismo del s. VI (GUTIÉRREZ LÓPEZ, 1997: lám f. 25-27).

En definitiva, los paralelos que se pueden establecer tanto en el Magreb como en la Península Ibérica nos muestran una cronología muy amplia para los aspectos técnicos y funcionales, mientras que las características tipológicas se asemejan más al denominado grupo del sureste de al-Andalus de los ss. VIII al $X$. En ese ámbito común se observan, no obstante, diferencias locales en los sistemas de sujeción de las piezas y en los procedimientos de decoración, caracterizándose las producciones de Nakūr por las bandas aplicadas, los motivos incisos y de pequeñas impresiones, junto con la ausencia de las asas de puente y la decoración mediante peines. Pero las características tipológicas comunes, como se puede deducir de los últimos ejemplos citados, se constatan en la Península a partir del s. VI, por lo que se puede inferir una cierta unidad a un lado y otro del Estrecho durante la Antigüedad Tardía y la Alta Edad Media, unidad tipológica que, por el contrario, no se da en la Península, donde se diferencian claramente las tipologías de la zona valenciana o de la Marca Media, y del mismo modo tambien son diferentes los tipos de cerámica modelada que aparecen en los yacimientos marroquíes de la Baja Edad Media.

\section{La aportación de los análisis de pasta}

Los análisis de pasta se han realizado por afinidad media no ponderada, sobre variables centradas reducidas correspondientes a los siguien- 
tes diecisiete componentes - determinados por fluorescencia $\mathrm{X}-\mathrm{K} \mathrm{K} 2 \mathrm{O}, \mathrm{MgO}, \mathrm{CaO}, \mathrm{MnO}, \mathrm{Al}_{2} \mathrm{O}_{3}$, $\mathrm{Fe}_{2} \mathrm{O}_{3}, \mathrm{SiO}_{2}, \mathrm{TiO}_{2}, \mathrm{Rb}, \mathrm{Sr}, \mathrm{Ba}, \mathrm{Ni}, \mathrm{Zn}, \mathrm{Cr}, \mathrm{Zr}, \mathrm{Ce}$, $\mathrm{V}$, mientras que, aunque hayan sido objeto de medición, $\mathrm{Na}_{2} \mathrm{O}, \mathrm{P}_{2} \mathrm{O}_{5}$ y La no han sido tomados en cuenta por la posible contaminación o imprecisión de las medidas que les afectaban.

El diagrama resultante (lám VIII) pone de relieve tres grupos, que numeramos de I a 3, estando el grupo intermedio dividido en tres subgrupos ( 2 a a $2 c$ ), así como varios casos aislados (a los que designaremos genéricamente como conjunto 4).

Grupo I. Reúne la casi totalidad de la cerámica común torneada pero sin vidriar, así como las muestras de arcillas recogidas in situ (lecho del wāđi y zonas próximas).

El hecho de que las arcillas estén agrupadas, en vez de distribuirse de forma homogénea dentro del conjunto de cerámicas a torno, no significa que unas y otras procedan de orígenes muy distintos dado que las composiciones analizadas son en ambos casos muy similares. La razón de este reagrupamiento debe ser más bien la mala calidad de las arcillas y el tratamiento que se les aplicó previamente a los análisis ${ }^{10}$.

La fabricación local de cerámica en hornos alfareros estaba sugerida ya por los hallazgos de superficie (atifles, ladrillos hipercocidos, etc.).

Grupo 2. Es el que más nos interesa aquí dado que asocia cerámicas modeladas procedentes por lo menos de tres orígenes distintos ( 2 a a $2 c$ ), lo que elevará a cuatro el número de centros de producción de este tipo de vasija teniendo en cuenta los números 18 y 38 del grupo anterior. Tampoco se puede excluir que los n`s 37 y 39 del subgrupo mediano (2b) tengan que disociarse de éste: son muy distintos de los demás y muy diferentes entre sí. En este caso pasarían a ser seis los centros de producción.
Grupo 3. Lo constituyen piezas vidriadas, que deben ser importadas, aunque -en esta fase inicial de la investigación- no se haya podido establecer su procedencia por falta de datos comparativos.

Otros: 4. De los ejemplos no adscritos a uno de los grupos principales podemos obtener también información: si los fragmentos de cerámica común $\left(n^{\circ} 2\right)$ y de teja $\left(n^{\circ} 17\right)$ situados a la derecha del primer conjunto pueden perfectamente considerarse como elementos marginados de aquél, no es el caso del $n^{\circ} 24$ que se desmarca por su poca proporción de cromo y su alta proporción en cesio y manganeso.

También son ejemplares aislados los números 3 (cerámica común), 22 y 23 (con vidriado melado oscuro interior y exterior), 34 (con decoración epigráfica).

Por último, los números 4, 5 y 27 constituyen quizá un grupo importado, coherente, al tener las cerámicas comunes 4 y 5 unas características tipológicas específicas.

El análisis de pastas además de resaltar la diversidad de procedencia de la cerámica a torno vidriada (para la que, en un primer tiempo, podemos sugerir al-Andalus e Ifrīqiya sin poder precisar más), confirma la producción local de una cerámica a torno de la que quedaría por saber de dónde proceden los modelos (¿imitación de modelos andalusíes, tradición magrebí propia o simple pertenencia a un conjunto post-romano común a las dos orillas?).

En cuanto a la cerámica a mano, que nos interesa especialmente aquí, la identificación de varios puntos de fabricación -ya sean cuatro o seis- da cuenta de un esquema de producción bastante clásico para un centro urbano de este tipo, que debía constituir un punto de intercambio privilegiado para las poblaciones que le rodeaban (recordaremos que Nakūr se implantó en el lugar de un zoco intertribal).

\footnotetext{
10 De hecho, las cerámicas que presentan un desengrasante abundante, pasan a la derecha de este grupo, más allá de las arcillas: caso de la teja $n^{\circ} 16$ y sobre todo de los dos fragmentos a mano $n^{\circ} 18$ y $n^{\circ} 38$.
} 


\section{La producción actual local (Banū War- yagal y Timsaman)}

Ya hemos tenido oportunidad de comentar que el asentamiento de Nakūr estaba situado en el límite entre Banū Waryagal y Timsaman, límite que sigue correspondiendo al curso del wādi Nakūr.

Esta estabilidad espacial de grupos que, por otra parte, han sabido mantener su coherencia cultural (organización tribal, lengua, etc.), confiere una mayor pertinencia a nuestras interrogaciones sobre el supuesto no-evolucionismo de las producciones cerámicas en sociedades habitualmente descritas como "tradicionales".

Para ser totalmente convincente nuestra aproximación hubiera tenido que seguir esta producción local a lo largo de los diez últimos siglos. Teóricamente hubiera sido posible: cuando desapareció Nakūr como ciudad, lo que hasta el momento había sido su puerto más próximo, al-Mazamma, se desarrolló como ciudad y tomó su relevo como centro estructurador del espacio regional; se apagó paulatina- mente a finales de la Edad Media. Desgraciadamente al-Mazamma no ha sido excavado, y las escasas fotografías del material cerámico recogido allí en los años treinta no incluyen más que piezas torneadas y vidriadas (COON, 1931: lám 4). Por tanto sólo podemos apreciar con más o menos precisión el punto de partida (las producciones del s. IX-X a partir de los sondeos realizados en el yacimiento) y el punto de llegada (la cerámica "tradicional" actual y subactual) a partir de los estudios etnoarqueológicos.

Empezaremos por este punto de llegada. Aunque no hayamos tenido oportunidad, en el marco limitado de nuestro proyecto, de desarrollar una investigación propia sobre el tema, disponemos por suerte de varios estudios etnográficos que, a pesar de haber sido concebidos según enfoques muy distintos del nuestro, nos aportan datos dignos de ser interpretados desde la perspectiva arqueológica. La primera descripción de la cerámica a mano de los Banū Waryagal se debe a D. M. Hart (HART, 1976: pp. 38-40 y 44)". Aunque, por enmarcarse en una obra de temática bastante más amplia, no profundiza mucho, vemos descritas en este trabajo

\begin{tabular}{|c|c|c|c|c|}
\hline Centro de producción ${ }^{12}$ & Mano de obra & Cocción & Decoración ${ }^{13}$ & Piezas fabricadas \\
\hline - Azrhâr & 3 mujeres & fosas & oxido de manganeso & $1,2,3 a, 12$ \\
\hline - Souânī & 3 mujeres & hoyos & fadiz & $6,12,13,14$ \\
\hline - Aït Kamral & 2 mujeres & hoyos & $?$ & 4,8 \\
\hline - Aitt Tighart & varias mujeres & fosas y hoyos & fadiz & $6,10,11,12$ \\
\hline - Tamâssīnt & varias mujeres & hoyos & fadiz & $6,7,10,12$ \\
\hline - Eranassane & 5 mujeres + I hombre & hoyo; $2^{\circ}$ : horno de pan & fadiz & $2,5,6,9,10,13$ \\
\hline - Idardoûchene & varias mujeres & fosas y hoyos & fadiz & $2,5,6,7,9,11,13$ \\
\hline - SidiYoussef & varias mujeres & fosas y hoyos & fadiz & $6,10,12$ \\
\hline - Ifasyane & varias mujeres & hoyos & fadiz & $6,7,10,12$ \\
\hline - Rwâdī & 4 mujeres & hoyos & fadiz & $2,3 a$ \\
\hline • (Zaouiia) Amlâh & I mujer & fosas y hoyos & fadiz & 5,12 \\
\hline - La' rī & I mujer & hoyos & bruñido & $3 c, 16$ \\
\hline - Azrhar Tarifa & I mujer & hoyos & fadiz+ carbón & $1,3,5,15,16$ \\
\hline - Akhchâh Oumrhâr & varios hombres & hornos de alfarería & \multicolumn{2}{|c|}{ cerámica al horno tipo Beni Sidal (Nador) } \\
\hline
\end{tabular}

I) No se recoge el vocabulario específico.

12 La ortografía de los topónimos es la empleada en el mapa IGN I/ 00000 Al Hoceïma n NI-30-XXI- I.

13 La confusión es total en la obra de VOSSEN y EBERT (1986) a propósito del pigmento utilizado para la decoración: "fadiz", "tinta vegetal", "alquitrán vegetal", están mencionados de forma totalmente aleatoria. En todo rigor el alquitrán vegetal (al-qațran, procedente del sabinal) no se emplea en Timsaman ni en Banū Waryagal pero sí en otras regiones del norte de Marruecos, tal como la de Taza. 
las principales características de las producciones de esta tribu: piezas cerámicas fabricadas a mano por mujeres, con arcilla rojiza local, secadas al sol antes de pulimentarlas con piedra pómez y posterior cocción en fosas, decoración geométrica pintada con pigmento hecho a partir de hojas secas de lentisco.

Posterior ha sido la investigación llevada a cabo por un grupo de etnógrafos alemanes sobre el conjunto de los alfares de Marruecos, lo que nos ha llevado a cartografiar así tanto los "talleres" de Banū Waryagal y Timsaman como los de las tribus vecinas, ofreciendo para cada uno de ellos unos datos descriptivos relativamente útiles (VOSSEN, EBERT, 1986: pp. 84-107; HAKENJOS, 1988: pp. 205-213).

Hemos intentado sintetizar esta última aportación en un cuadro recapitulativo (cf. infra) que necesita no obstante unos comentarios más amplios aunque sólo sea por una evidente falta de rigor, por parte de aquellos autores, en la exposición de los datos recogidos.

El mapa de los lugares de fabricación de cerámica a mano de Banū Waryagal y Timsaman (lám IX) muestra un cierto desequilibrio entre una tribu y otra ( I I en Banū Waryagal y 3 en Timsaman) así como una clara concentración en la zona central de cada uno de los territorios concernidos. Este último punto no se debe a una mayor presencia de arcillas aprovechables, sino más bien a la proximidad de los potenciales puntos de venta (zocos) ${ }^{14}$ y de utilización (núcleos de población) : Imzuren y sobre todo Ajdir en Banū Waryagal ${ }^{15}$, Suk Jamis y Boudinar en Timsaman.

Se confirma también que toda la producción cerámica de las dos tribus es familiar y que en ella sólo intervienen mujeres ${ }^{16}$, que en gran parte se encargan también de su difusión en zocos de mujeres. Esta cerámica local a mano se cuece en fosas de tamaño variable ${ }^{17}$ o simples hoyos cuya localización varía de una cocción a otra y en los que las piezas están dispuestas mezcladas y cubiertas por el combustible siendo éste recubierto a su vez por una capa de tejas; la frecuencia de estas "hornadas" tiene que amoldarse a las demás actividades domésticas y agrícolas del grupo.

Las pastas son más bien pajizas en Banū Waryagal y más rojizas en Timsaman. La decoración recurre exclusivamente a pigmentos vegetales, el fadiz cuya composición y utilización habían sido descritas, años antes, por A. Delpy: "este colorante se obtiene machacando en un mortero de madera hojas verdes de lentisco (ar. drū; berb. fadis) y algunas vainas frescas de algarrobo. El líquido se corta con agua y se conserva en un cuenco no más de un día" (DELPY, 1974: p. 31). Sólo se menciona el uso de óxido de manganeso en Azrhar (Banū Waryagal). En un único caso, el de Eranassane, se señala una segunda cocción (en horno de pan) de las piezas ya decoradas. Aunque nos inclinamos a pensar que, tal como lo recuerda A. Delpy (DELPY, 1974: p. 31) ${ }^{18}$, después de pintarlas, las piezas se calientan sobre un anafre o se colocan en un horno de pan en fase de enfriamiento pero con temperatura todavía suficiente para que el pigmento se oscurezca hasta adoptar el aspecto negro brillante deseado.

La ornamentación, que destaca en negro sobre la pasta, tiende a invadir toda la superficie, en particular en Banū Waryagal, y más en piezas de servicio que en las de almacenamiento, o sobre todo de cocina: círculos y rosetas enmarcadas en cuadros, motivos de origen animal muy estilizados, etc. (lám $X)^{19}$. Bien es cierto que son justamente las piezas decoradas que

\footnotetext{
I4 Se trata, en particular de zocos de mujeres, institución muy propia de esta zona rifeña.

I5 Este último sucedió a al-Mazzama como centro de poder hasta la fundación de Al-Hoceima por los españoles.

16 En un caso marginal de Banū Waryagal, Eranassane, el hijo de la familia se ha incorporado recientemente al proceso de fabricación, mientras que el alfar exclusivamente masculino de Akhchah Oumrar de Timsaman produce cerámica a torno, cocida en hornos, y es el resultado de una importación tecnológica reciente desde los Banū Sidal de Nador.

17 Hasta 2,50 m × 4,00 m en Azrhar de los Banū Waryagal.

I 8 En el Zerhūn, J. Herber (HERBER, 1922: p. 249) habla de una segunda cocción, muy rápida.

19 En tribus vecinas de Banū Waryagal, como Banū Bū Frah, la decoración puede limitarse a simples manchas organizadas geométricamente.
} 
hasta ahora, han sido objeto de la atención de los investigadores. Nótese también que no parece que se recurra a impresiones $\mathrm{o}$ incisiones al contrario de lo observado en las producciones medievales.

Hay que resaltar que las piezas así fabricadas cubren todo el abanico de las necesidades domésticas ${ }^{20}$ :

- Recipientes para cocción de alimentos: Marmitas y ollas (gedra -ar.-, aqnūš -ber:-) [I], cazuelas (țatâint ț) [2], platos para cocer el pan (ferrah) [3a y 3b] a veces de gran tamaño (anhdam) [3c].

- Contenedores de líquidos: Transporte. Cántaros (agdūrlaqdūhn, țagambwāț tagamburțt) [4], recipiente para el ordeño (țaqsrayțtaqasriț/taqasrašt) [5]. Almacenaje y servicio. Botijos (taqdaht $t$ ) [6], jarros, jarras y asimilados (taqdiht) $[7,8,9]$, (tatast ț) $[10,11]$.

- Contenedores de sólidos y semi-sólidos: Servicio. Platos, cuencos y escudillas (tahbiț) (tahbsilt) [12a, I2b]; cuenco alargado (tamqaddart??) [13], alguno de ellos dobles [14].

- Otros objetos: Coladores/cuscuseros (keskes) [15], anafres (amaŷmarlțimaŷmarț) [16].

La amplitud formal de la producción no deja de presentar una extraña anomalía (ver cuadro): en aquellas descripciones etnográficas de "talleres", las menciones de ollas y cazuelas que, recordémoslo, son mayoritarias en las cerámicas a mano halladas en la excavación de Nakūr, son muy escasas. Se pueden proponer varias explicaciones (desde que las vasijas tradicionales hayan sido suplantadas ahora por otro tipo de objetos -cerámica a torno, ollas de fundición, etc.- hasta que una producción, cuya estética era en esencia más discreta, haya llamado menos la atención de los investigadores, sin que ninguna de estas explicaciones parezca verdaderamente convincente.
Una cosa parece segura: los puntos de similitud entre cerámica medieval y actual son muy pocos. Una forma muy específica de la producción de los actuales Banū Waryagal, la jarrita de dos asas con apertura ancha de bordes rehundidos, țatast (lám X), brilla por su ausencia dentro de las formas medievales, por no hablar de la omnipresencia hoy de la decoración pintada, más que discreta en la Edad Media.

La simple comparación entre la cerámica a mano fabricada en los siglos IX-X por un grupo tribal y la que este mismo grupo fabrica en el siglo XX muestra, pues, una drástica evolución morfológica y ornamental. Independientemente de interrogarse sobre la estabilidad real, o no, de la estructura del grupo en cuestión, conviene tomar en cuenta la información que se puede sacar de un avatar de la historia de los propios Banū Waryagal. En efecto, sabemos que el sultán Muhammad b. Abd al-Raḥmān desplazó entre 1859 y 1879 una importante población rifeña y la instaló en el macizo del Zerhūn (región de Meknes); se trataba esencialmente de Banū Tuziñ y de Banū Waryagal (HERBER, 1922: p. 24I; DELPY, 1974: p. 24). Casi un siglo después del corte así impuesto, las cerámicas fabricadas por los grupos del Rif y los del Zerhūn siguen siendo idénticas, lo que nos obliga a concluir que ora la evolución de esta cerámica a mano beréber es muy lenta -no apreciable en la escala de un siglo, es decir de tres generaciones-, ora procede de forma no progresiva, por "saltos" y discontinuidades cuyas causas quedarían por esclarecer.

Desgraciadamente, de otra hipotética segmentación de los Banū Waryagal, muy anterior, no se ha podido obtener información; en efecto la presencia en la Edad Media de un grupo de Banū Waryagal ha sido localizada en la actual provincia de Castellón a través del análisis toponímico. Aunque se acepte el análisis propuesto ("Benirrage $=$ Vinarragell $=$ Banī $U$ Ryāgel": SELMA, 1992: p. 62), la escasa cerámica asociada no permite concluir. Tenemos constancia también de la presencia de "Banū Wara-

20 La nomenclatura de las formas según VOSSEN y EBERT (1986) no es satisfactoria. Aunque basándonos en ella, hemos intentado corregirla y completarla a partir de varias fuentes y encuestas, con la dificultad añadida de que el vocabulario descriptivo varía bastante de un grupo a otro. 
$\hat{y}$ ūl" en época relativamente temprana en Mojáfar (küra de Mérida) (IBN HAYYĀN, 198I: p. 183); no obstante ignoramos casi todo al respecto: su importancia numérica, los rasgos de su cultura material y sobre todo su procedencia ${ }^{21}$.

En todo caso, si las semejanzas observadas en ciertas ocasiones entre algunas series cerámicas medievales de la Península y producciones norteafricanas subrecientes son innegables (DELAIGUE, 1983-84), las explicaciones del fenómeno serán más complejas de las que hasta ahora han sido avanzadas, suponiendo ante todo un mejor conocimiento de la evolución durante toda la Edad Media de la cerámica a mano magrebí, e implicando muy verosímilmente unos reajustes cronológicos.

\section{CONCLUSIONES}

Ante todo, se confirma que la cronología de la cerámica de Nakūr se ha de centrar en los ss. IX-X (frente a lo publicado por N. Benco que propuso una fecha más tardía), de acuerdo con los paralelismos que se pueden establecer para el conjunto de la producción y de piezas claramente importadas; datación nuestra de acuerdo además con la información ofrecida por las fuentes escritas.

Dentro de la cerámica fabricada a torno rápido -que no es el objeto del presente estudio-, se pueden discernir una producción local de piezas no vidriadas y unas importaciones (ante todo desde al-Andalus, pero con algunos ejemplares procedentes también del Magreb central y/o de Ifríaiya) que dan cuenta de la plena integración de la capital rifeña en las redes económico-políticas del momento.

La cerámica a mano de Nakūr, que representa un 30\% del conjunto de este material (sensiblemente más que para un asentamiento contemporáneo tal como puede ser al-Bașra -pero curiosamente menos que en Badīs en época más tardía-), se limita a tres tipos de vajilla de cocina: marmitas, cazuelas y tapaderas, lo que demuestra una eficaz gestión tecnológica de los recursos respecto a las necesidades.

A partir de las características comunes a toda la producción se observa una cierta variedad en la composición de las pastas así como en los tamaños de las vasijas, de donde se puede deducir un número elevado de productores con una distribución posiblemente de tipo familiar, según unos esquemas parecidos a los de la fabricación y distribución tradicionales subactuales, procesos ligados pues a la estructura social del entorno.

En cuanto a la funcionalidad y tipología general, se pueden relacionar con el grupo del sureste de al-Andalus contemporáneo, si bien con notables diferencias en los elementos de sujeción y, sobre todo, decorativos. Esta diferencia decorativa también se da entre los distintos lugares del grupo peninsular pero en éste las producciones son más regulares, obedeciendo quizá a una elaboración y distribución de tipo local, frente a la familiar que se detecta en Nakūr. A dicho grupo se le pueden encontrar unos orígenes preislámicos pero se diferencia claramente de otros grupos contemporáneos, emirales, en la Península.

Con respecto al resto de los yacimientos marroquíes, parece ser que la producción a mano de vajilla de cocina prosigue a lo largo de la Edad Media, pero con notables diferencias tipológicas - salvo en el caso de lo poco publicado de al-Bașra - mientras que, si se aceptan los datos de Badīs, en la Baja Edad Media se daría una proliferación de tipos y funciones nuevas para la cerámica modelada a mano (lo que, por otra parte, echa por tierra el tópico de un abandono paulatino de esta técnica, ligado a un "progreso tecnológico" lineal e ineluctable).

Lo que parece incuestionable es la nula relación con la cerámica tradicional, bien definida en esta zona por las observaciones etnográficas,

2I En efecto, no debemos olvidar que los Banū Waryagal/Banū Waraŷū, que pertenecen a la rama nafza de los sanhāŷa, estaban también localizados en el valle de Baȳāya -Argelia actual- : IBN JALDUN, I978: I, pp. 227, 253; II, pp. 56, I23. Sobre los Banū Waraȳūl en la Península Ibérica: DE FELIPE, 1997: pp. 238-242 
en cuanto a la funcionalidad, tipología y decoración, lo que es más destacable en el presente caso pues se trata de la presumible continuidad de un mismo grupo tribal. En consecuencia, en lo que se refiere a la cerámica no existe un continuum a lo largo de las épocas, sino que se dan importantes soluciones de continuidad que deben obedecer a razones históricas. En el ejemplo estudiado, la cerámica a mano de Nakūr de los ss. IX-X, se vincula más estrechamente con un limitado espacio del Mediterráneo occidental que con las producciones posteriores de la zona rifeña, si bien el estudio de la cerámica a torno deberá precisar el alcance de estas relaciones, tanto en el marco espacial como a nivel cronológico.

\section{BIBLIOGRAFÍA}

ACIÉN ALMANSA, Manuel; MARTÍNEZ MADRID, Rafael (1989): "Cerámica islámica arcaica del Sureste de alAndalus", Boletín de Arqueología Medieval. 3, pp. I09-I22.

AMAHAN, Ali (199I): "La poterie des Jbala", Jbala. Histoire et société. Études sur le Maroc du Nord-Ouest. Casablanca-París, pp. 431-445.

BALFET, Hélène (1977): Poterie féminine et poterie masculine du Maghreb, Tesis Doctoral, París.

BAZZANA, André; CRESSIER, Patrice; ERBATI, Larbi; MONTMESSIN, Yves; TOURI, Abd el-Aziz (1983-84): "Première prospection d'archéologie médiévale et islamique dans le Nord du Maroc (Chefchaouen-Oued LaouBou Ahmed)", Bulletin d'Archéologie Marocaine. XV, pp. 367-450.

BAZZANA, André; MONTMESSIN, Yves (1995): "Quelques aspects de la céramique médiévale du Maroc du Nord", Actes du 5 ème Colloque sur la Céramique Médiévale. Rabat. Novembre 1991. Rabat, pp. 24I-259.

BENCO, Nancy L. (1987): The Early Medieval Pottery Industry at al-Basra, Morocco, BAR International Series 34I, Oxford.

BENCO, Nancy L. (1989): "Diversity in Ceramic Production: A Case Study from Medieval North Africa", en Ch. L. Redman (ed.), Medieval Archaeology. Papers of the Seventeenth Annual conference of the Center for Medieval and Early Renaissance Studies. New York, pp. 97- I I 8.

CAGIGAS, Isidoro de las (1951): Dinastías menores del Maghrib: tomo I: los Banu șālih de Nakur. Tetuán.

CASTILLO GALDEANO, Francisco; MARTÍNEZ MADRID, Rafael (1993): "Producciones cerámicas en Bâิŷāna", en A. Malpica Cuello (ed.), La cerámica altomedieval en el sur de al-Andalus. Primer encuentro de Arqueología y Patrimonio. Granada, pp. 67- 116.
COON, Carleton S. (1931): Tribes of the Rif. Harvard African Studies 9, Harvard-Cambridge.

DE FELIPE, Helena (1997): Identidad y onomástica de los beréberes de al-Andalus. Madrid.

DELAIGUE, Marie-Christine (1983-84): "Possible influence berbère dans la céramique médiévale de la région valencienne", Bulletin d'Archéologie Marocaine. XV, pp. 493-522.

DELPY, André (1974): "Poteries rustiques modelées par les femmes du Nord marocain", Cahiers des Arts et Techniques d'Afrique du Nord. 7, pp. 23-36.

DEVISSE, Jean; PICON, Maurice (1995): "Questions de pots: à propos des céramiques de Tegdaoust (Mauritanie)", Actes du 5 ème Colloque sur la Céramique Médiévale. Rabat. Novembre 1991. Rabat, pp. 235-240.

ELHRAIKI, Rahma (1989): Recherches ethnoarchéologiques sur la céramique du Maroc. Tesis Doctoral, Lyon.

FERNÁNDEZ SOTELO, Emilio (1988): Ceuta medieval. Aportación al estudio de las cerámicas (s. X-XV). Ceuta.

FUERTES SANTOS, Ma del Camino; GONZÁLEZ VIRSEDA, Marina (1994): "Nuevos materiales cerámicos emirales de Cercadilla (Córdoba): ensayo tipológico", Anales de Arqueología Cordobesa. 5, pp. 277-30I.

GÓMEZ BECERRA, Antonio (1993): "Cerámica a torneta procedente de "El Maraute" (Motril). Una primera aproximación a la cerámica altomedieval de la costa granadina", en A. Malpica Cuello (ed.), La cerámica altomedieval en el sur de al-Andalus. Primer Encuentro de Arqueología y Patrimonio. Granada, pp. 173-191.

GOZALBES BUSTO, Guillermo (1989): "El reino de Nakur en la Edad Media", en id., Estudios sobre Marruecos en la Edad Media. Granada, pp. 27-69.

GUTIÉRREZ LÓPEZ, José María ( 1997): "I I.3. Las cerámicas tardorromanas a torno lento y modeladas a mano", en J.j. López Amador (ed.), Aportaciones al proceso histórico de la ciudad de El Puerto de Santa María. La intervención arqueológica en la plaza de Isaac Peral. Cádiz, pp. 104-I 3.

GUTIÉRREZ LLORET, Sonia (1993): "La cerámica paleoandalusí del sureste peninsular (Tudmīr): producción y distribución (siglos VII al X)", en A. Malpica Cuello (ed.), La cerámica altomedieval en el sur de al-Andalus. Primer encuentro de Arqueología y Patrimonio. Granada, pp. 37-65.

HAKENJOS, Bernd (1988): Marokkanische Keramik. Stuttgart.

HART, David Montgomery (1976): The Aith Waryagar of the Moroccan Rif. An Ethnography and History. Viking Fund Publications in Anthropology, 55, Tucson.

IBN HAYYĀN ( 1981 ): Al-Muqtabis V, trad. Ma. J. Viguera, F. Corriente. Zaragoza.

HERBER, J. (?)(1922): "Techniques des poteries rifaines du Zerhoun", Hespéris. II, pp. 242-253.

IBN JALDUN (1978): Histoire des Berbères et des dynasties musulmanes de l'Afrique septentrionale, trad. de Slane. París. 
LAROUI, Abdallah (1975): L'histoire du Maghreb. Un essai de synthèse. París.

MARION, Jean (1957): "Les ruines anciennes de la région d'Oujda", Bulletin d'Archéologie Marocaine. II, pp. I I 7-163.

NAVARRO LUENGO, I.; FERNÁNDEZ RODRÍGUEZ, L.F.; SUÁREZ PADILLA, J. (1997): "Cerámicas comunes de época tardorromana y bizantina en Málaga", Figlinae Malacitanae. La producción de cerámica romana en los territorios malacitanos. Málaga, 1997

ONRUBIA PINTADO, Jorge (1995): "Les tessons peints de Ghar Cahal (Maroc setentrional). Encore des recherches sur l'antiquité de la céramique modelée et peinte en Afrique du Nord", L'homme méditerranéen. Mélanges offerts à Gabriel Camps. Aix-en-Provence, pp. 127- 142.

PICON, Maurice (1995): "Pour une relecture de la céramique marocaine : caractéristique des argiles et des produits, techniques de fabrication, facteurs économiques et sociaux", Ethno-archéologie méditerranéenne (A. Bazzana y M.-Ch. Delaigue, eds.). Madrid, pp. |4|-| 58.
REDMAN, Charles L. (1983-84): "Survey and test excavation of six medieval islamics site in northern Morocco", Bulletin d'Archéologie Marocaine. XV, pp. 31 I-350.

SELMA, Sergi (1992): "L'ordenació del territori andalusí. Uns exemples al Nord Valencià", Buttletí de l'Associació Arqueòlogica de Castelló. 12, pp. 6I-66.

SIRAJ, Ahmed (1995): L'image de la Tingitane. L'historiographie arabe médiévale et l'Antiquité nord africaine, Collection de l'École Française de Rome 109. Roma.

TAOUCHIKHT, Lahcen (1995): "La céramique médiévale de Sijilmasa: approche générale", Actes du 5ème Colloque sur la Céramique Médiévale. Rabat. Novembre 1991. Rabat, pp. 227-234.

VOSSEN, Rüdiger, EBERT, Wilhem (1986): Marokkanische Töpferei. Töpferorte und-zentren. Eine Landesaufnahme (1980). Bonn. 


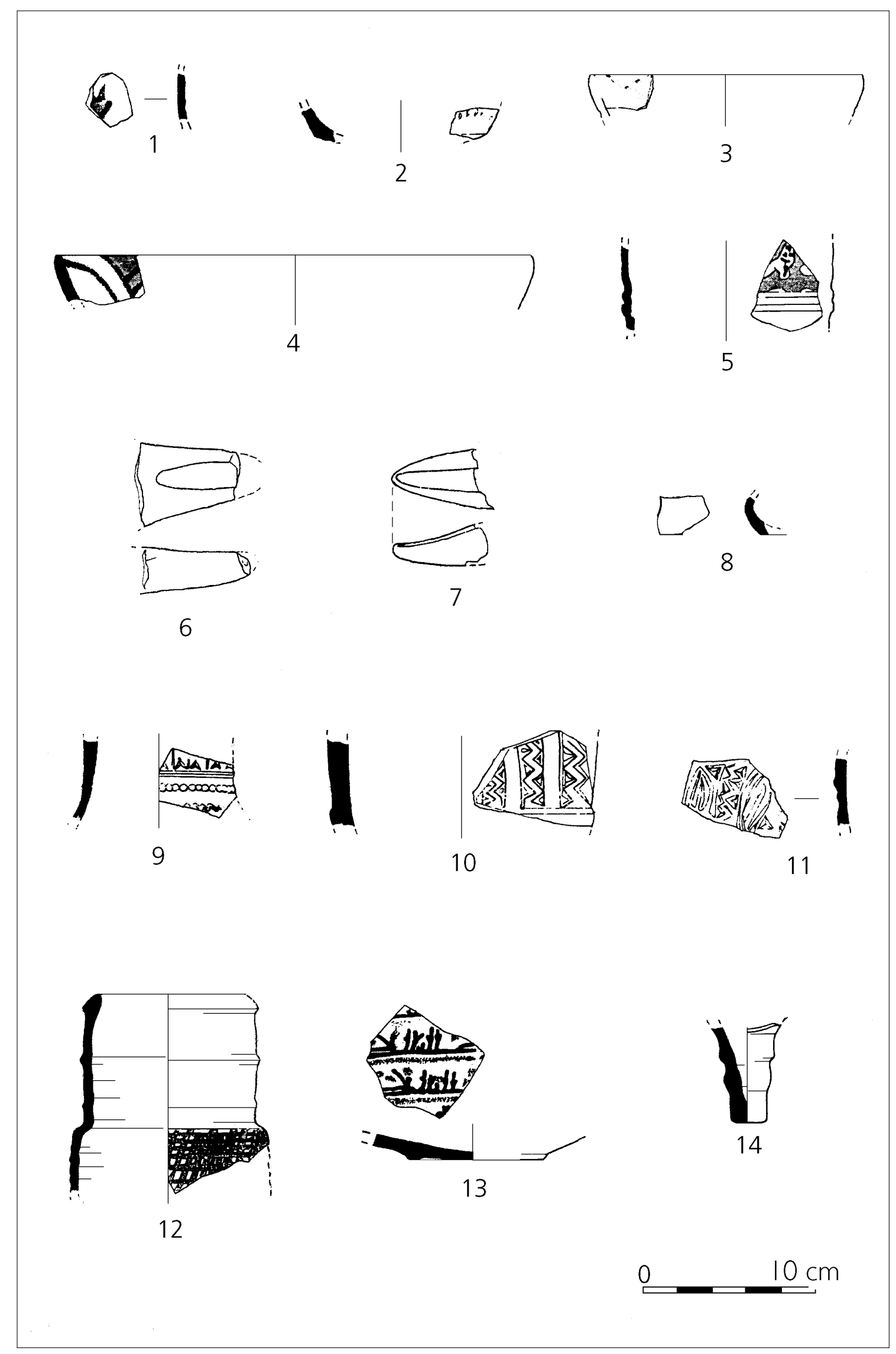

Iám I. Nakūr: cerámica medieval fabricada a torno rápido (producciones locales e importaciones). 


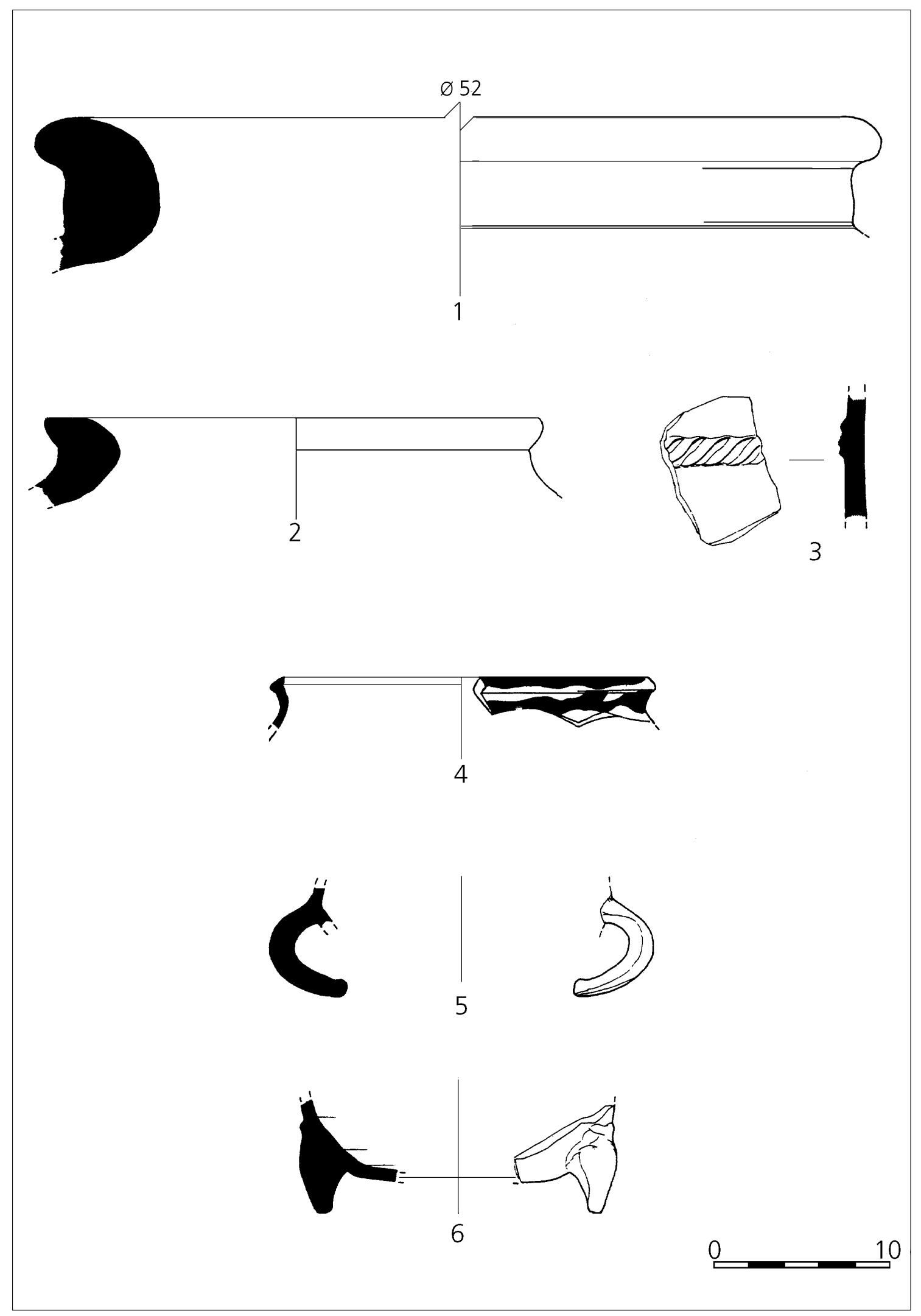

lám II. Nakūr: cerámica medieval fabricada a torno rápido (producciones locales e importaciones) 

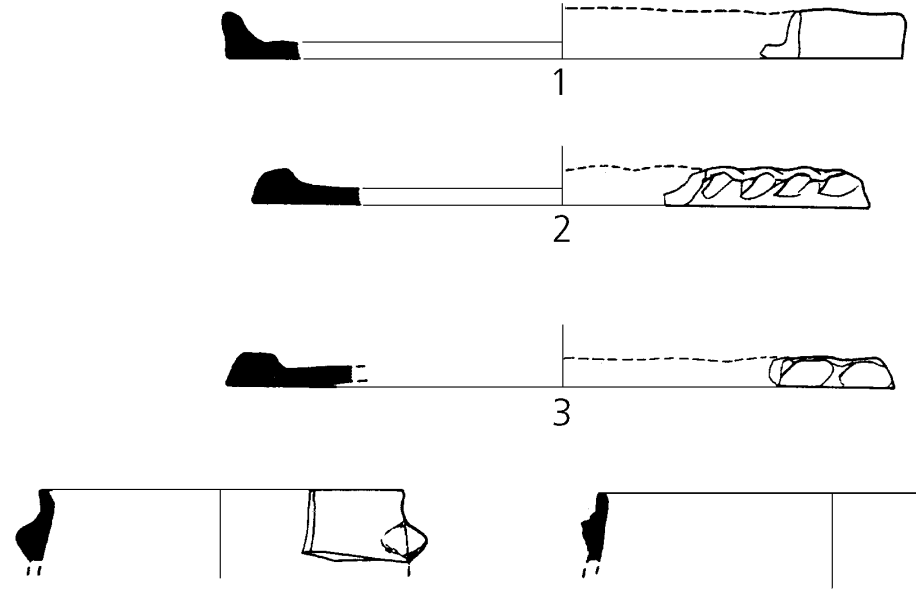

4

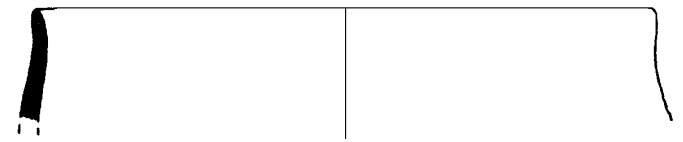

6
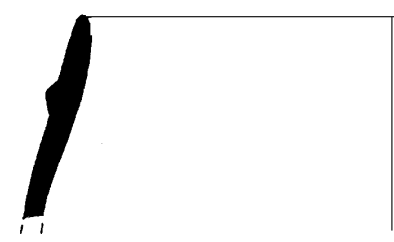

7
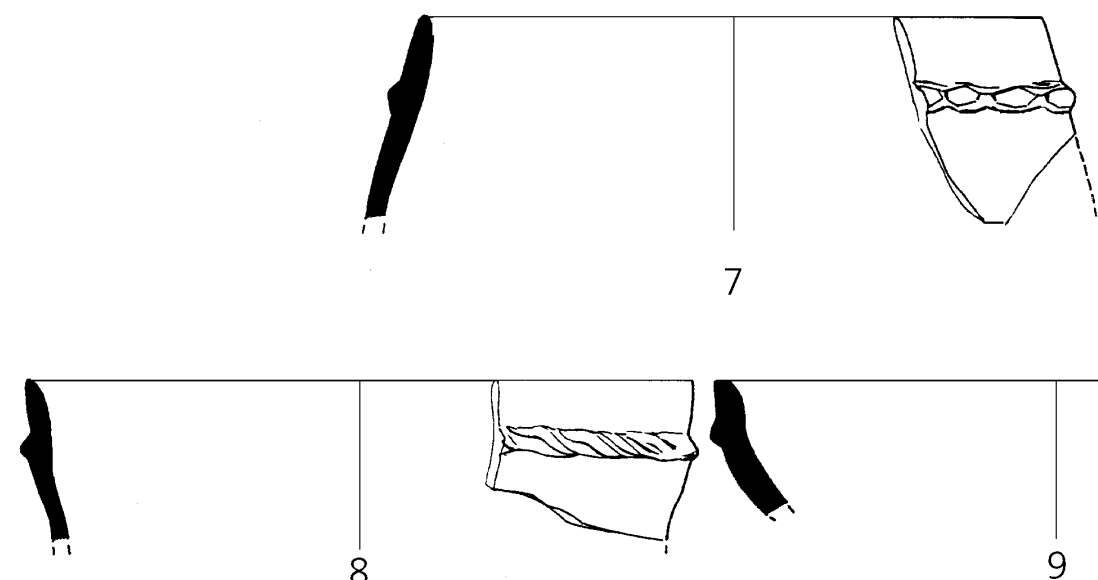

8

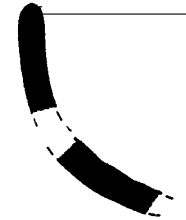

10

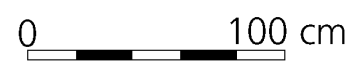

lám III. Nakūr: cerámica medieval modelada a mano; tapaderas ( I-3), marmitas (4-7) y cazuelas (8-10). 

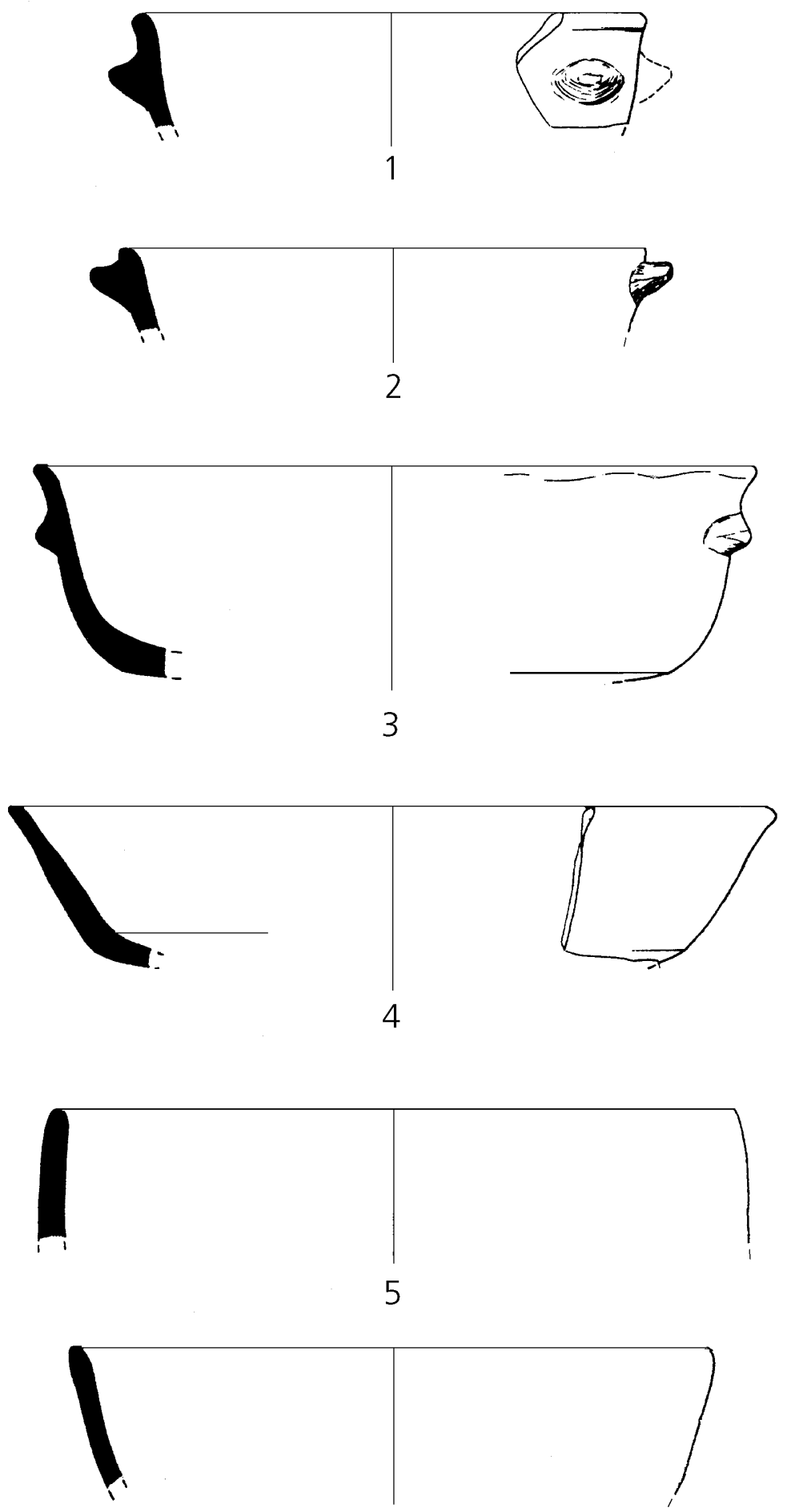

6

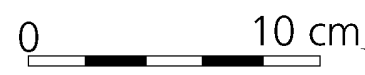

lám IV. Nakūr: cerámica medieval modelada a mano; cazuelas. 


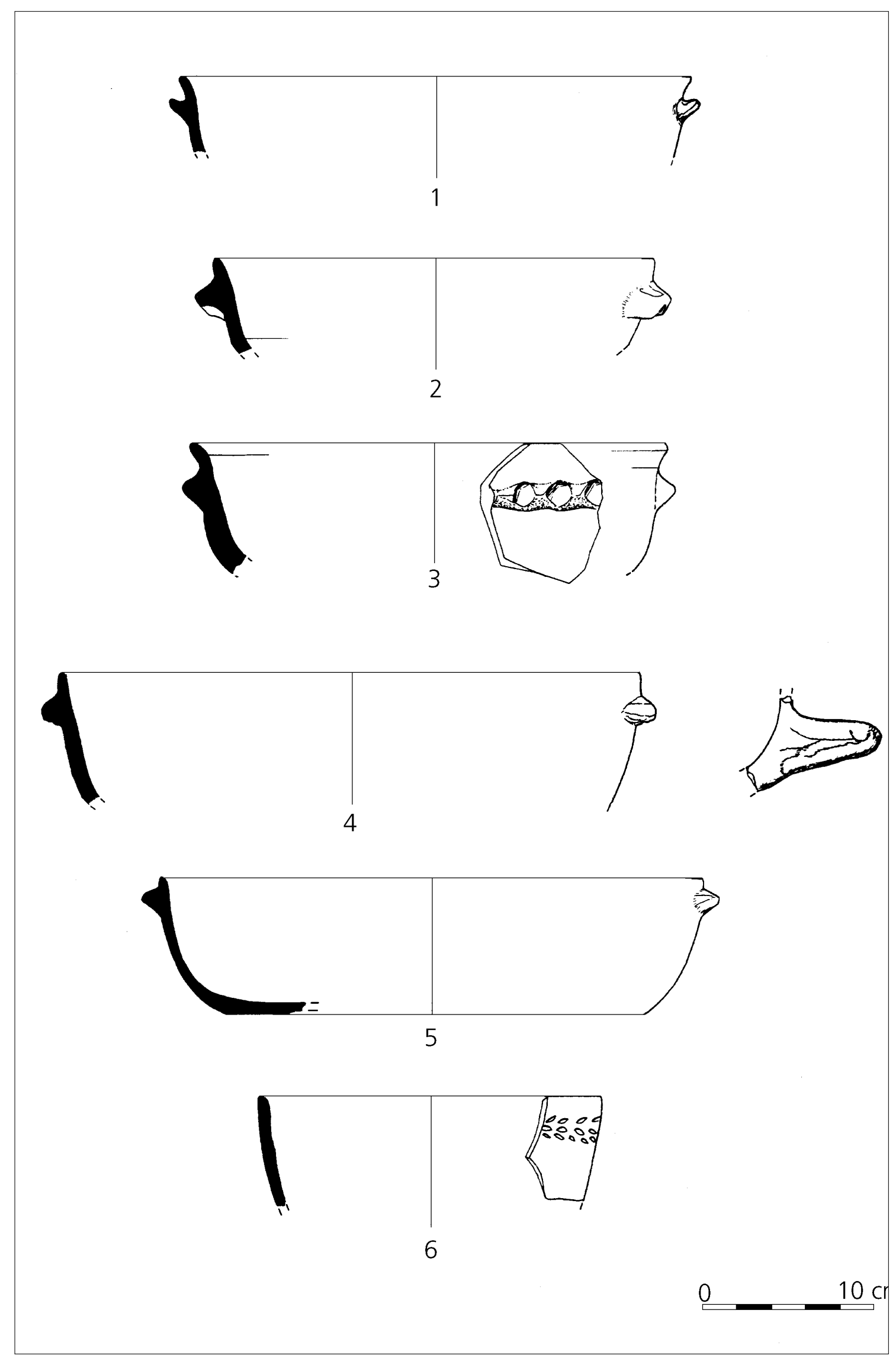

lám V. Nakūr: cerámica medieval modelada a mano; cazuelas. 

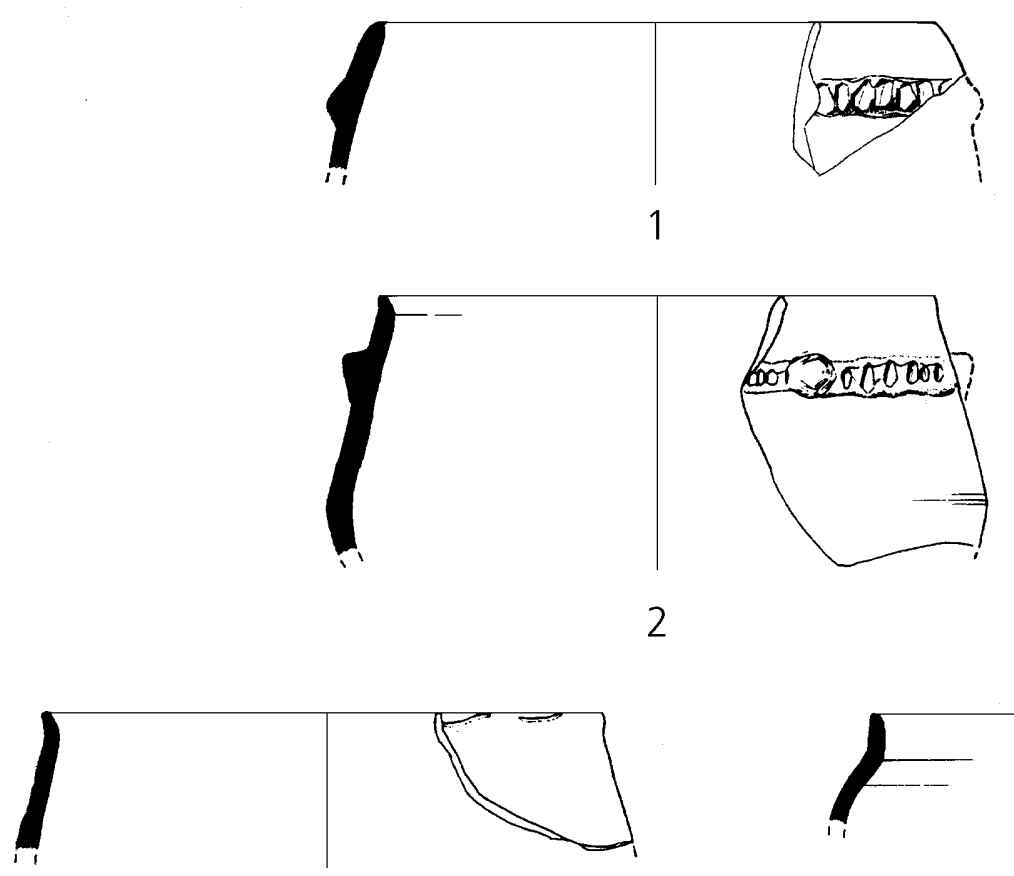

3

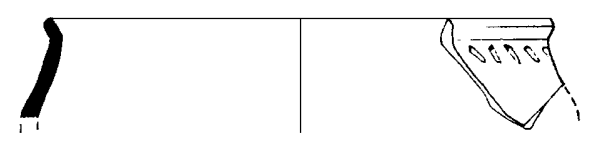

5

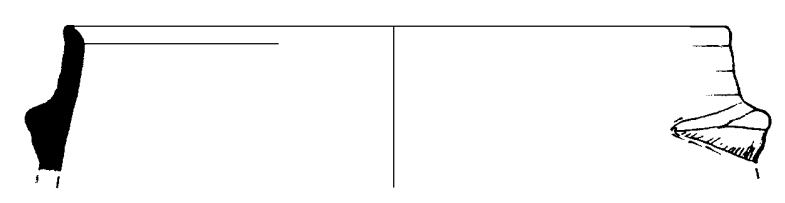

7
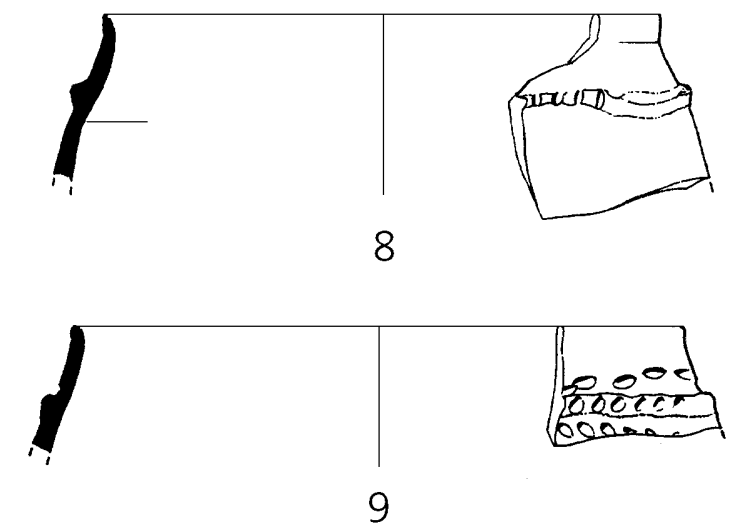

Iám VI. Nakūr. cerámica medieval modelada a mano; marmitas. 

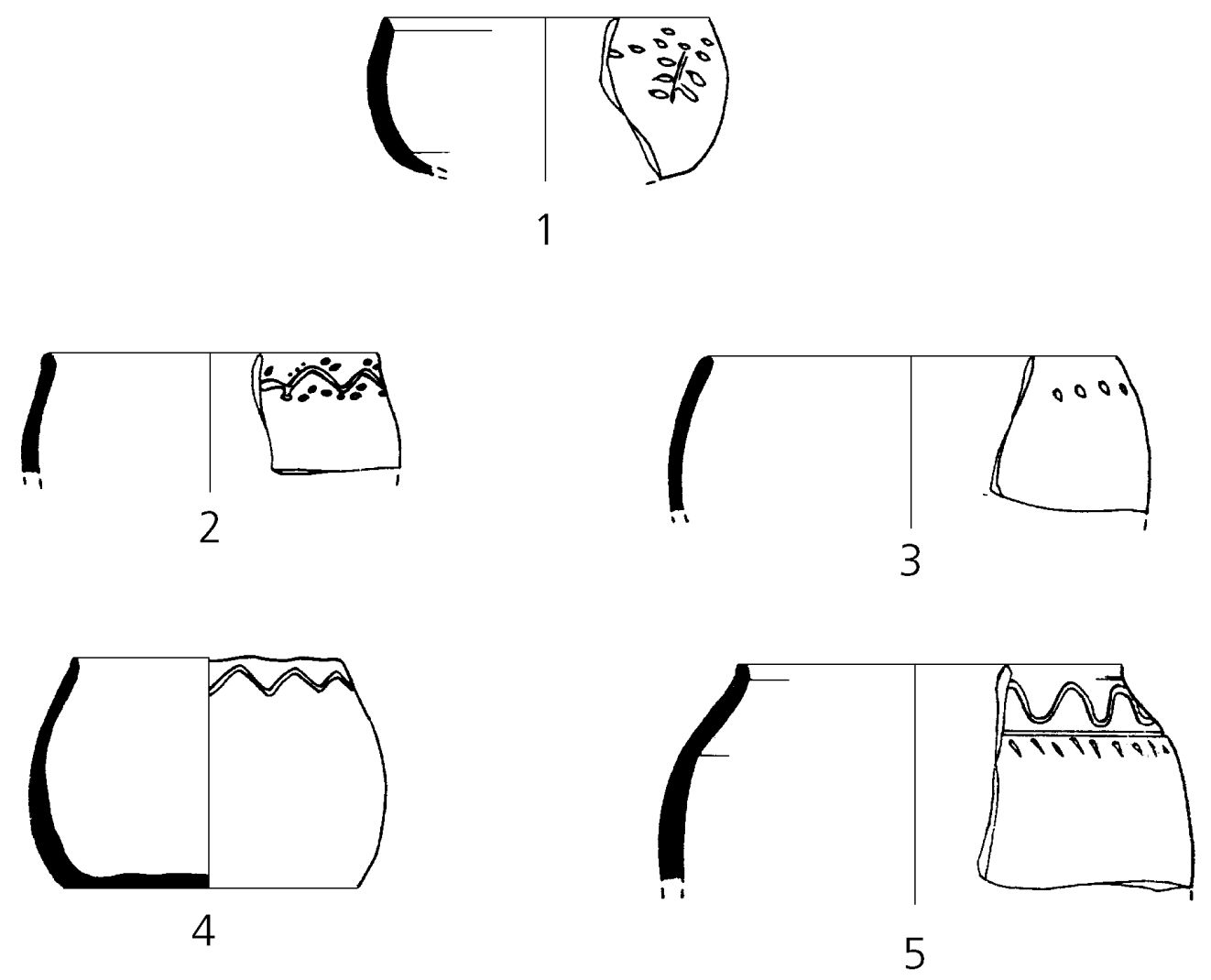

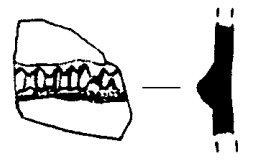

6

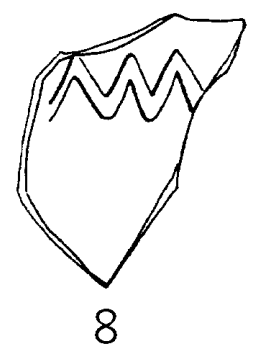

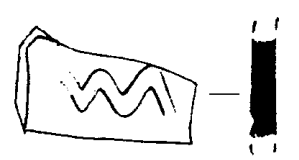

7

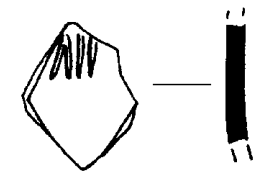

9

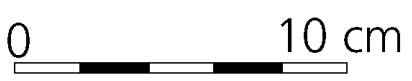

lám VII. Nakūr: cerámica medieval modelada a mano; marmitas. 


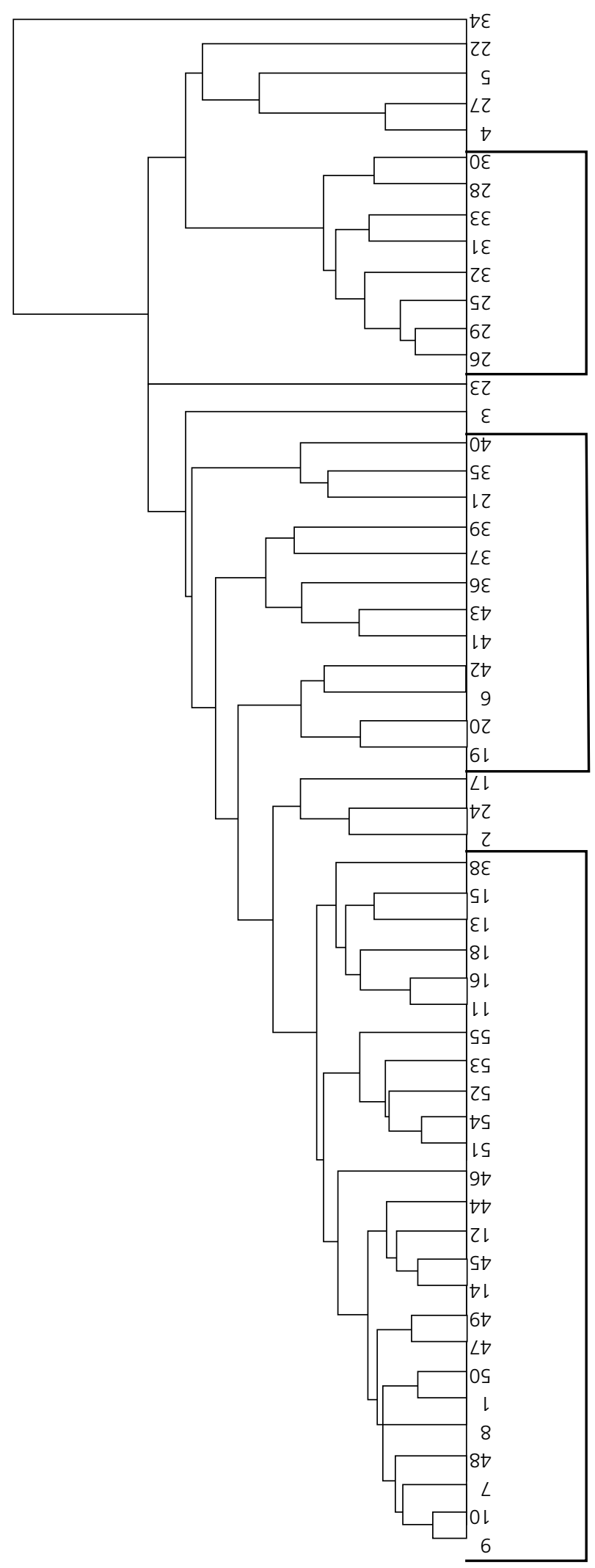

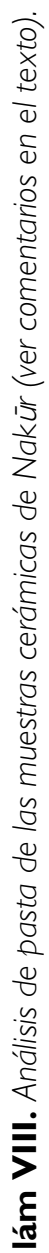




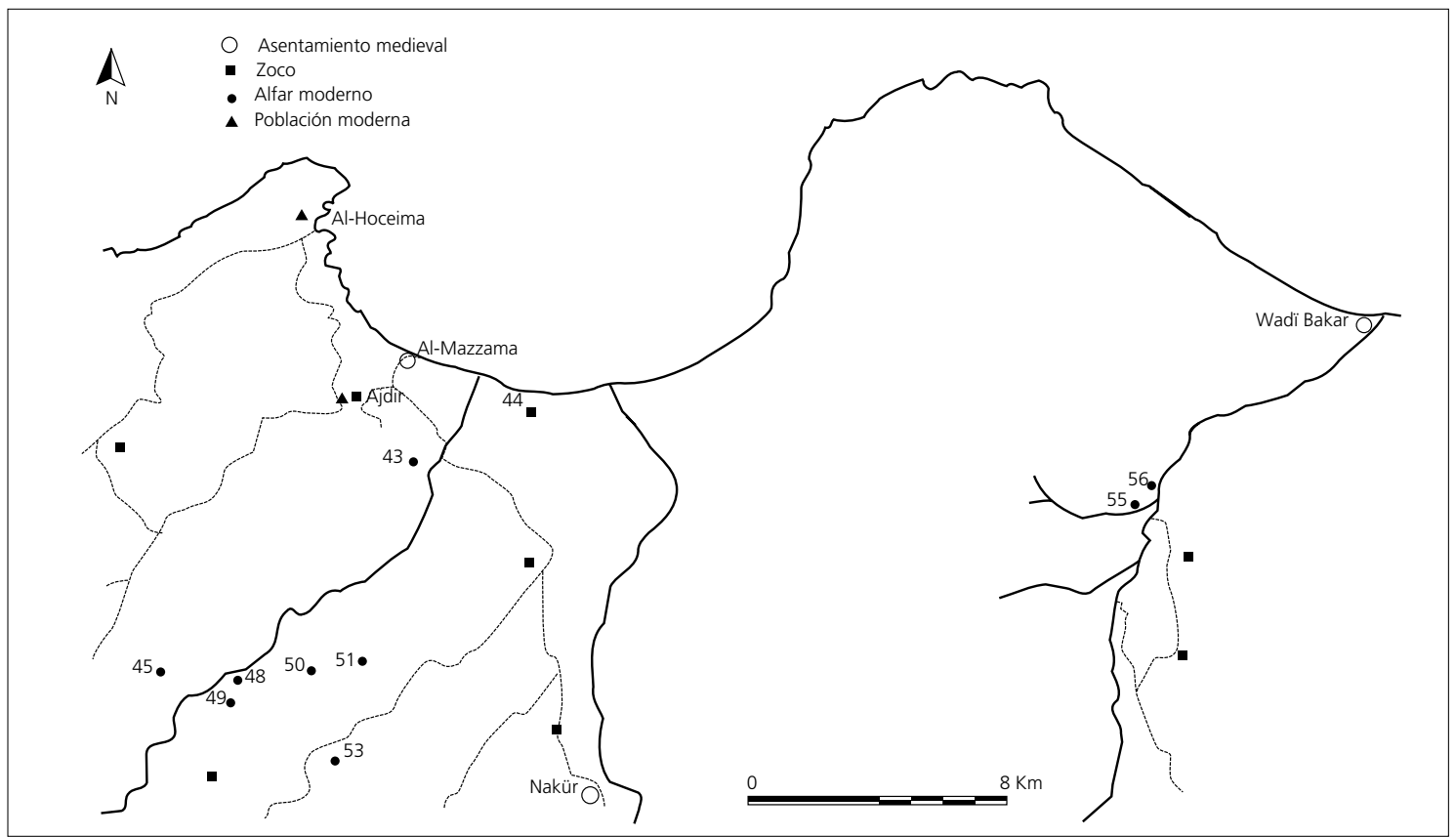

Iám IX. Mapa de distribución de los puntos de fabricación de cerámica a mano en Banū Waryagal y Timsaman y de sus puntos privilegiados de venta (s. $X X)$. Posiciones respectivas de los sucesivos centros de ordenación del territorio, del siglo VIII al siglo XX: Wādi Bakar, Nakür, al-Mazzama, Ajdir, Al-Hoceima.
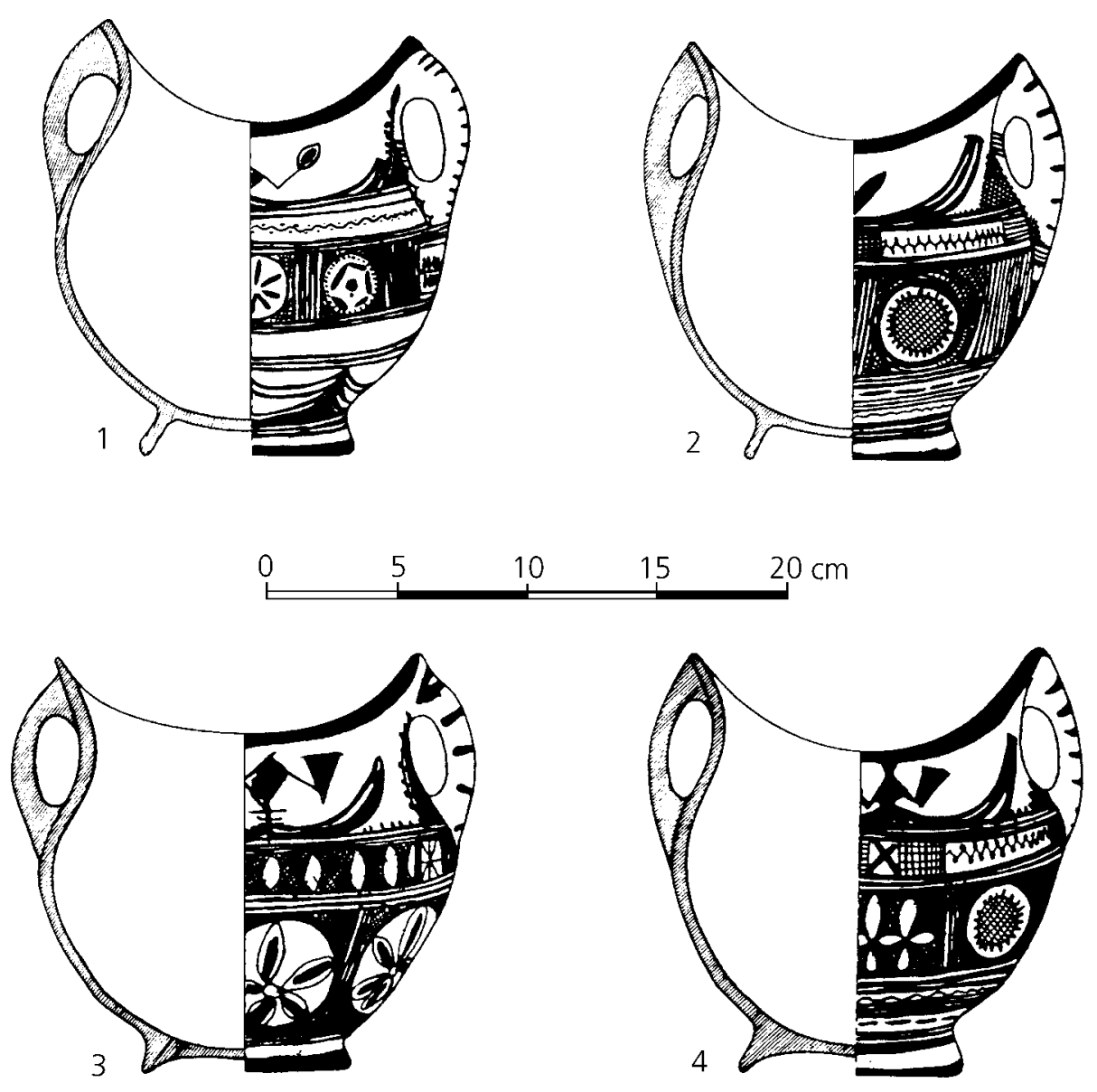

lám X. Jarritas (țațast) pintadas de Banū Waryagal (según HAKENJOS 1988, lám 9, p. 2 I 3). 